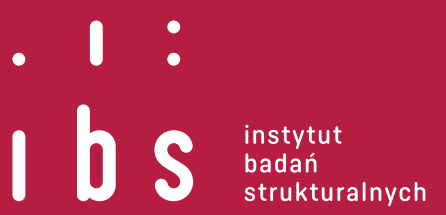

IBS WORKING PAPER 08/2019

AUGUST 2019

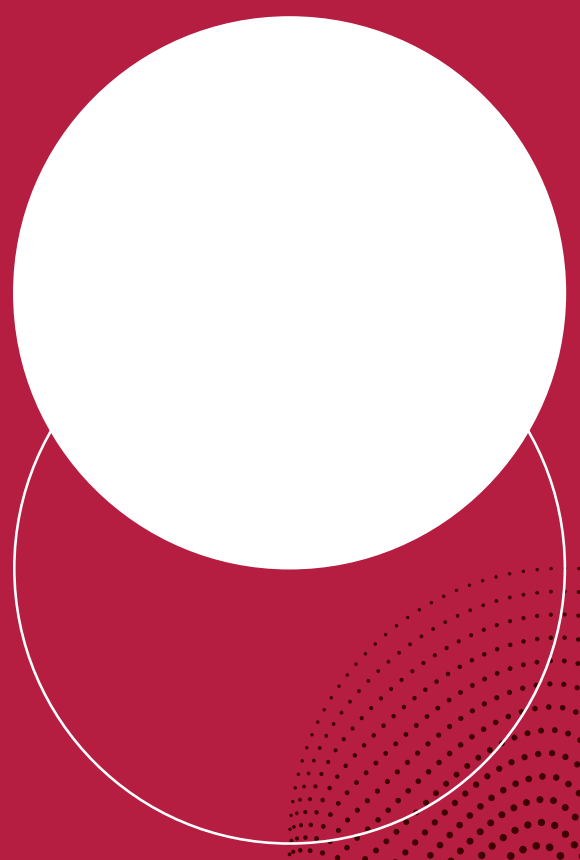

\title{
ON THE COMPETITIVE EFFECTS
} OF SCREENING IN PROCUREMENT

Adam Pigoń Gyula Seres

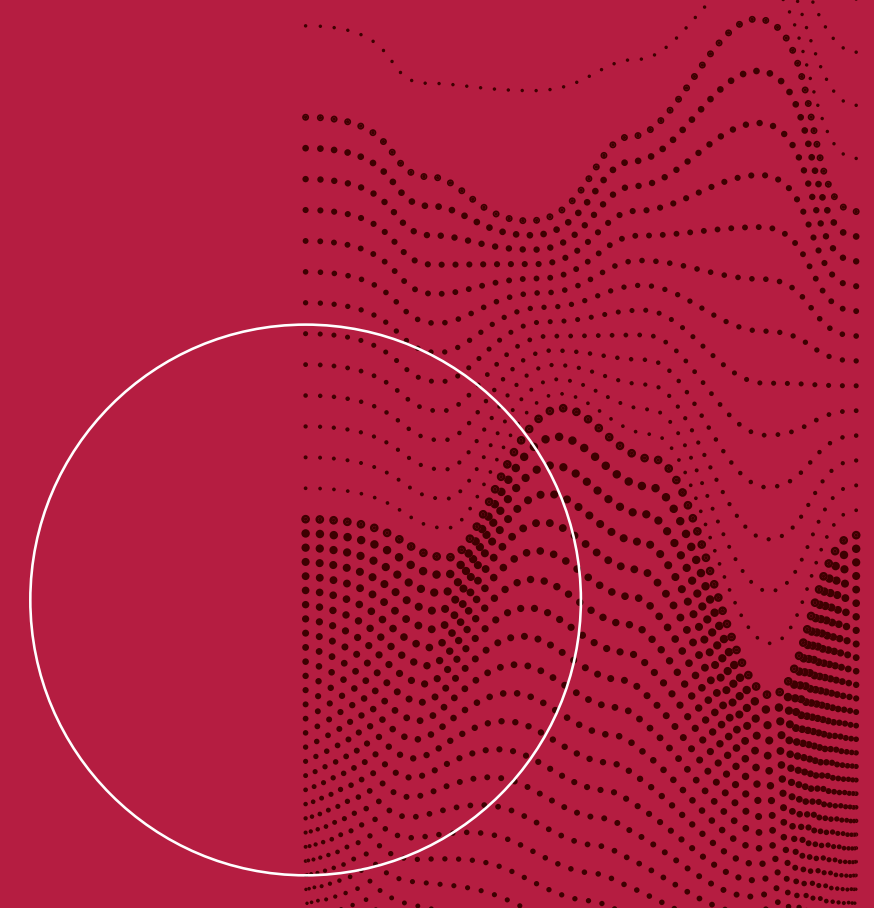




\title{
ON THE COMPETITIVE EFFECTS OF SCREENING IN PROCUREMENT*
}

\author{
Adam Pigoń $^{\dagger}$, Gyula Seres ${ }^{\ddagger}$
}

\begin{abstract}
Procuring authorities frequently use screening in order to mitigate risky bids. This study estimates the effect of bid screening and litigation on entry and bidding using a unique data set on highway construction procurement auctions in Poland. The market exhibits a screening method that ex post selects eligible offers. We demonstrate with an empirical model that this method disproportionately affects small firms and creates a barrier to entry. Our results suggest that screening increases bids by two channels. First, it directly inflates bids as well as decreasing entry. Second, in a competitive market, lower entry also inflates bids and prices.
\end{abstract}

Keywords: Procurement, Auctions, Market Design, Litigation

JEL Classification: H57, D44, D47, L5

\footnotetext{
${ }^{*}$ We are grateful to Estelle Cantillon, Olga Chiappinelli, Francesco Decarolis, Reto Föllmi, Dakshina De Silva, Nicola Dimitri, Elisabetta Iossa, Winfried Koeniger, Georgia Kosmopoulou, Daniel Marszalec, Vlada Pleshcheva, Almuth Scholl, Arthur van Soest, Giancarlo Spagnolo, and participants of ERAIE 2018, TiLEC Seminar, University of Groningen Economics Seminar, BCCP Forum, DIW Industrial Economics Seminar, WIEM 2018, Joint Economic PhD Seminar in Konstanz, and PhD Seminar in St.Gallen for their valuable comments. We would like to thank Przemysław Rzeźniewski for his detailed comments on GDDKiA procurement procedures and abundant anecdotal evidence on them. We thank Tadeusz Śmietanka for comments on the Polish construction industry.

${ }^{\dagger}$ Institute for Structural Research (IBS), Warsaw. E-mail: adampigon@gmail.com.

${ }^{\ddagger}$ Humboldt University of Berlin, Faculty of Economics \& Business Administration and Tilburg Law \& Economics Center. Email: gyula.seres@hu-berlin.de.
} 


\section{Introduction}

Public procurement represents, on average, nearly $13 \%$ of the GDP and $29 \%$ of government expenditure in OECD member countries (OECD, 2016). As most public contracts are awarded by highly regulated procedures, their institutional framework has a profound effect on procurement outcome and market competition. In principle, the outcome is determined by a ranking and awarding mechanism based on either price or a combination of price and quality. However, the winning bidder may fail to deliver the contracted good if its cost is uncertain and eventually exceeds the price or, in this context, the winning bid. One of the most prevalent methods to mitigate excessive losses to the procurer is an ex post screening of offers. This procedure results in the rejection of potentially problematic bids. After this, the contract is awarded by ranking the remaining offers. ${ }^{1}$ Public procurement differs from other bidding markets in that bids are accompanied by a mandatory complex documentation of the provided good or service. Given these features, an automatized evaluation of offers is not possible. Rejection rates are determined by the ability of bidders to deliver feasible technical and financial plans. As legal remedies are available, bidders may also use litigation against their opponents.

This article contributes to our understanding of screening by analyzing its competitive effects. The tradeoff between mitigating risk and prices is well understood. However, there is less attention paid to the resulting asymmetry between firm types. As our estimates demonstrate, it creates a barrier to entry for small firms and decreases overall entry, boosting prices. In our interpretation, screening works like an inverse preferential program that results in a higher market concentration. We use a unique dataset on highway procurement auctions in Poland from the period between 2005 and 2018. After the accession to the European Union in 2004 , the country experienced an inflow of highly capitalized foreign firms, which actively participated in the emerging construction boom. This setting provides a clear identification of large foreign bidders, which have accumulated substantial experience in competitive bidding. One can reasonably expect that large firms have a decisive advantage in delivering eligible bids and hence in avoiding rejection. Our data, provided by the national highway procurement authority GDDKiA and the responsible court of appeals $\mathrm{KIO}$, covers all major contracts on national roads awarded through competitive procedures from the sample period, to a total value of 35.7 billion EUR ( 41 billion USD) in 2018 prices.

We develop an entry and bidding model, in which bidders form rational expectations about screening outcomes. In doing so, we can rely on observed bids, detailed information on procurement rules and project characteristics, as well as on the outcome of court appeals related to screening. First, we estimate the effect of firm size on screening outcomes with a logit model, also controlling for court appeals. We find evidence of divergent performance between firms of different sizes, with small firms suffering significantly higher rejection rates. We also show that litigation, although its effect is significant on the final screening outcome, plays a lesser role in shaping the market. Second, we impute the estimated rejection probabilities in a model with bidding and entry. Evidence shows that bids are directly driven by expected screening outcomes. Moreover, they have a profound effect on entry. This is consistent with our hypothesis about the heterogeneous effect of screening. If firms with smaller barriers to entry perform better in administrative and legal tasks, constrained firms face disproportionate obstacles. Our estimates are robust with respect to different measures of firm size.

\footnotetext{
${ }^{1}$ In the literature, and in the corresponding statutory law, the expressions 'screening' and 'bidder qualification' are used interchangeably. For clarification, we focus on ex post screening, which is arguably more efficient than ex ante bidder qualification under some conditions (Gillen, Gretschko, and Rasch, 2017).
} 
The reason behind the strong entry effects of auction rules is explained by the winner-takes-all characteristic of auctions. In order to foster entry, the auctioneer must create a system with a significant chance of winning for potential entrants. It is a well-supported argument regarding dynamic competition with endogenous entry that favoring weak players fosters competition in the long term. The key idea is that, under symmetry, efficient bidders have a high probability of winning. Hence, incentives for the entry of weaker firms are limited by a low chance of winning. To mitigate the entry effect and improve long-run efficiency, governments can enact preference programs favoring small- and medium-sized enterprises (Krasnokutskaya and Seim, 2011). As this article shows, screening has the exact opposite effect and lowers efficiency by favoring large firms. We also address the potential benefits of screening. Using a parametric regression survival-time model, we find no evidence that using stricter screening measures improves contract completion times.

Large-stake public procurement auctions draw significant attention in the literature. The main idea behind studying entry is the dichotomy of rewarding efficiency and encouraging competition. The theory and empirical literature on procurement has long emphasized the role of entry on prices and shows that bidder asymmetries may be harmful but can be mitigated by appropriate policy measures. This general idea in auction theory can be attributed to Myerson, 1981. Li and Zheng, 2009 estimate that the effect of bidder asymmetries is ambiguous in public procurement markets. Athey, Coey, and J. Levin, 2013 suggest that subsidizing small bidders increases their revenues and profits, with little efficiency cost. Bid screening, which is predominantly featured in this article, is studied by Decarolis, 2014 and Branzoli and Decarolis, 2015 in the context of performance. They conclude that screening prevents performance from worsening, but reduces cost savings and induces delays in the awarding procedure. Coviello et al., 2017 emphasize the role of efficient legal procedures and show that the courts' performance can result in extensive delays in the procurement procedure. ${ }^{2}$

This article is structured as follows. Section 2 describes relevant details of the Polish highway procurement market and provides a descriptive analysis of the dataset. Furthermore, in Section 3 we build a theoretical model and enumerate its predictions. Sections 4 and 5 present the main empirical results. The article concludes with a discussion on results and alternative policy tools.

\section{Data}

Relevant details of procurement procedures prevalent in highway construction in Poland are presented in Subsection 2.1. Our data is compiled from two distinct sources, which is the procurement authority, described in Subsection 2.2, and the court of appeal, described in Subsection 2.3.

\subsection{Procurement Process}

The state of the Polish infrastructure before joining the EU in 2004 was characterized by a deteriorated state of the road network, lack of highways, and the absence of beltways bypassing population centers.

\footnotetext{
${ }^{2}$ The number of other policy-related factors affecting bidding and entry is large. Other seminal papers address the role of publicity requirements (Coviello and Mariniello, 2014), information disclosure by the procurer (De Silva et al., 2008), preparation costs (De Silva, Jeitschko, and Kosmopoulou, 2009), subcontracting terms (Miller, 2014), the possibility of renegotiating contracting terms (Bajari, Houghton, and Tadelis, 2014), and penalties (Lewis and Bajari, 2014). Moreover, Asker and Cantillon, 2008 and Asker and Cantillon, 2010 deal with awarding mechanisms, discussing price-only and scoring auctions.
} 
Government objectives and newly available EU funds resulted in a large-scale construction program. ${ }^{3}$ We study contracts for new or significantly upgraded roads that are administered by the General Directorate of National Roads and Highways (GDDKiA), a government agency responsible for procuring roads that are classified as national roads. ${ }^{4}$ Tenders in our dataset come from the period 2005-2018. National roads in Poland are classified as A-class roads, S-class roads or G/GP roads, distinguished by their technical characteristics like the minimum distance between junctions, maximum allowed elevation, lane width, maximum bearing capacity, etc. ${ }^{5}$

Auctions follow a one-stage or a two-stage format. ${ }^{6}$ In the one-stage auction, the procurer specifies all details about a given auction and then asks all interested bidders to submit their offers. Firms may bid individually or form a consortium. In the latter case, a lead partner must be named from the list of consortium members.

Two-stage auctions follow different procedures. All firms interested in building a given road are assessed based on financial requirements which prescribe sufficient liquidity and open credit lines. Moreover, bidders must prove that they have sufficient technical and human resources to complete the project. If firms decide to form a consortium, its members and a leader must be specified before entering the first stage. The number of bidders invited to the second round shall lie between 5 and 20 . If there are less than 5 bidders the auction is repeated, and if there are more than 20 bidders fulfilling financial criteria, the most experienced ones are selected. ${ }^{7}$ The second stage of an auction admits the preselected bidders. Between the two stages a detailed specification of the road is published, if it was not disclosed prior to the first stage. In the second stage, all accepted firms make a decision if they submit a bid.

When submitting a bid, each bidder must put a predefined, auction-specific deposit. This sum is always requested and lies between 50,000 and $20,000,000$ PLN or between 0.07 and $5.49 \%$ of the final contract value. $^{8}$ The full sum of the deposit is returned to all auction participants, with the exception of a winner that is unwilling to sign the contract. The winner of an auction may be asked to submit an additional deposit, vouching for his works. If it is requested, it may amount to between 5 to $10 \%$ of the contract value. In the text, these two deposits are called 'Deposit I' and 'Deposit II', respectively. In order to use a comparable scale, Deposit I is calculated as the percentage value of the required amount with respect to the winning bid.

The procurer does not disclose any information on the firms submitting bids before the end of the bidding period. Both in one- and in two-stage auctions, firms are allowed to ask questions about details of the road specifications and their documentation. These inquiries are publicly available and, therefore, firms can infer from them who may be potentially interested in submitting bids. Moreover, in two-stage auctions the list of preselected companies passing the first stage is publicly available prior to submitting bids in the

\footnotetext{
${ }^{3}$ For details on infrastructure developments in Poland, see Goujard, 2016. The scale of the projects is illustrated by maps in Figure 3 in Appendix A.

${ }^{4}$ The agency name in Polish is 'Generalna Dyrekcja Dróg Krajowych i Autostrad' (GDDKiA). We do not analyze renovation works and small upgrades but focus on works specified in various editions of 'National Program of Road Construction' ('Krajowy Program Budowy Dróg'), an official government document on the national roads building program

${ }^{5}$ National roads make up about $4.7 \%$ of all roads in Poland, when weighted by their length, but they comprise all A- and S-class highways in the country.

${ }^{6}$ The Polish Public Procurement Law was passed in 2004 and modified following the ratification of EU Directives 2004/18 and 2014/24. We exclude directly awarded contracts from our sample.

${ }^{7}$ Data on first-stage results and participation is, unfortunately, not available. To the best of our knowledge, in the whole sample period, no auction featured less than 5 first-stage participants.

${ }^{8}$ It means that deposits lie between 11,500 and 4,600,000 EUR using the exchange rate from September 2018.
} 
second stage of an auction. This implies that firms may be aware of their potential competitors when they formulate their offers.

In both types of auction formats, screening is a system of pass/fail criteria. Bids can be rejected based on a faulty cost estimation or by not meeting the financial requirements. Moreover, abnormally low tenders may also get rejected. Finally, bidders can be rejected if they fail to prove their construction capabilities, i.e. by not having enough human or technical capital stocks. There are no preferential programs for domestic or small and medium-sized enterprises. ${ }^{9}$

A contract can get dissolved if a firm does not keep up with the specified progress in the construction. Objective difficulties like disadvantageous weather conditions may be a sufficient excuse to explain a delay in the contract. After dissolving a contract, another auction is published to resume construction works.

The awarding criteria are specified by the procurer, it is either lowest-price rule, essentially a first-price sealed-bid auction, or a scoring rule. ${ }^{10}$ The latter encompasses price, quality and completion time being the awarding criteria. Weights for these dimensions vary between auctions. Price determines $60-95 \%$ of the score with $90 \%$ being the weight in the majority of cases. ${ }^{11}$

Bidders compete for construction contracts that may be one of four types: 'build', 'project \& build' (P\&B), 'reconstruction' or 'continuation' works. The first two types can be granted for a construction of new roads and in the 'project \& build' contract a construction company is responsible not only for building a road but also for preparing a detailed road project on its own. In the 'build' contract-type a company builds a road according to a project specified by another company. ${ }^{12}$ 'Reconstruction' and 'continuation' contracts are granted for upgrades of existing roads and the continuation of works when a previous contract was dissolved, respectively.

Auction participants can appeal for a reversion of decisions to the National Chamber of Appeal (KIO), ${ }^{13}$ a court specializing in the decisions of contracting public authorities. ${ }^{14}$ When the auction procedure is lawfully finished, contractors can protest any GDDKiA decisions in regular courts only. Appeals to KIO can pertain, among others, firms' protests against rejections of their own bids, claims that a single or multiple other bidders should be rejected or may involve the collective actions of many firms against certain aspects of a given procurement procedure.

\footnotetext{
${ }^{9}$ Unlike a number of procurers, GDDKiA does not apply partial qualification, which would mandate subcontracting for winners. For an example of this type of screening system, see Moretti and Valbonesi, 2015.

${ }^{10}$ This awarding criterion appears under other labels in legal documents (Dimitri, Piga, and Spagnolo, 2006). EU Directive 2004/17/EC and 2004/18/EC refer to it as best price-quality ratio, whereas the current Directive 2014/24/EU uses the term most economically advantageous tender (MEAT).

${ }^{11}$ Completion time may determine between 5 and $30 \%$ of the total score, while quality lies between 5 and $15 \%$. Time to completion stands for a maximum number of months within which a company pleads to finish the contract and quality is a commitment to repair works after delivery at his own expense. The procurer specifies the limits for both best potential quality and time declarations. In some of the most recent auctions, the quality component of the score is augmented with more specific requirements (having engineers with adequate experience, securing certain skidproof characteristics of a road, etc.)

${ }^{12} \mathrm{~A}$ company preparing a project is chosen in another independent public procedure. GDDKiA decided to introduce 'P\&B' contracts in order to smooth the construction process by reducing potential inconsistencies between projects and their execution.

${ }^{13} \mathrm{KIO}$ or 'Krajowa Izba Odwoławcza' in Polish.

${ }^{14}$ Appeal fees paid to KIO are about 2000-3000 EUR, final costs are typically no higher than 5000-6000 EUR. Costs of appeals in regular courts can be as high as millions of euros. The aforementioned expenses comprise only filing fees and court costs and do not include other legal bills.
} 
Table 1. Summary statistics of data on bids and auctions.

\begin{tabular}{lccc}
\hline & \multicolumn{2}{c}{ Awarding mechanism } & \\
\cline { 2 - 3 } & Lowest Price & Scoring & All \\
\hline Auctions & 188 & 175 & 363 \\
\hline One stage & 72 & 28 & 100 \\
Two stages & 116 & 147 & 263 \\
\hline Bids & 1,493 & 1,386 & 2,879 \\
Accepted bids & 1,364 & 1,061 & 2,425 \\
Rejected bids & 129 & 325 & 454 \\
\hline Mean bid (in mln PLN) & 473.2 & 448.7 & 462.5 \\
Mean price (in mln PLN) & 423.3 & 408.2 & 416 \\
Maximum price (in mln PLN) & 2149.2 & 2195.9 & 2195.9 \\
Minimum price (in mln PLN) & 4.6 & 35.4 & 4.6 \\
\hline Mean \# of bidders & 7.94 & 7.92 & 7.93 \\
\hline Mean \# of & 0.85 & 0.27 & 0.57 \\
minor consortium members & & & \\
\hline Mean length (in km) & 13.6 & 13.2 & 13.4 \\
\hline A-class roads & 46 & 17 & 63 \\
S-class roads & 86 & 131 & 217 \\
G/GP-class roads & 56 & 27 & 83 \\
\hline Dissolved contracts & 15 & 2 & 17 \\
\hline
\end{tabular}

\subsection{Auctions and Bids}

Our data contains 363 auctions that started between January 2005 and September 2018 and finished before December 2018. ${ }^{15}$ All contracts are signed for a major road project coordinated by the procurement authority GDDKiA. The data includes 188 lowest-price and 175 scoring auctions. Table 1 presents summary statistics separately for the two awarding criteria. In what follows, we express all bids in Polish złoty (PLN) in September 2018 prices. ${ }^{16}$ The total contract value in the sample period is 35.7 billion EUR, that is, about $7.6 \%$ of the nominal GDP in 2017. The descriptive statistics reveal a number of interesting patterns. Most mean road characteristics are comparable between scoring and lowest-price auctions. On average, 7.93 bidders competed for a contract.

Figure 1 displays the number of scoring and lowest-price auctions for each year, showing all scoring procedures in a single set. The figure also shows the distribution of one and two-stage auctions over time, as well as the distribution of contract types in the sample period.

The data highlights two important features. Firstly, there is a gradual policy shift from first-price to scoring formats, the latter becoming dominant in 2013. In the last two years of the observed period the new mechanism was used solely. Secondly, the timing of auctions is bimodal, with most taking place in the periods 2008-2009 and 2013-2014. ${ }^{17}$

\footnotetext{
${ }^{15}$ One may argue that data from that period may be distorted by lower markups and falling backlog due to the Great Recession, as evidenced by Gugler, Weichselbaumer, and Zulehner, 2015. However, Poland enjoyed a robust and stable growth during the entire period.

${ }^{16}$ In September 2018, 1 PLN was equal to about 0.27 USD or 0.23 EUR.

${ }^{17}$ This pattern may be explained by parliamentary election years (2011 and 2015) or the 2012 UEFA European Championship co-organized with Ukraine. We believe the most plausible explanation is that EU budgets have sevenyear horizons, the first being in the years 2007-2013 and the other one being in 2014-2020, because European funds constitute a significant fraction of the overall funds spent on road investment.
} 
Figure 1. Number of auctions across years by auction or contract type.
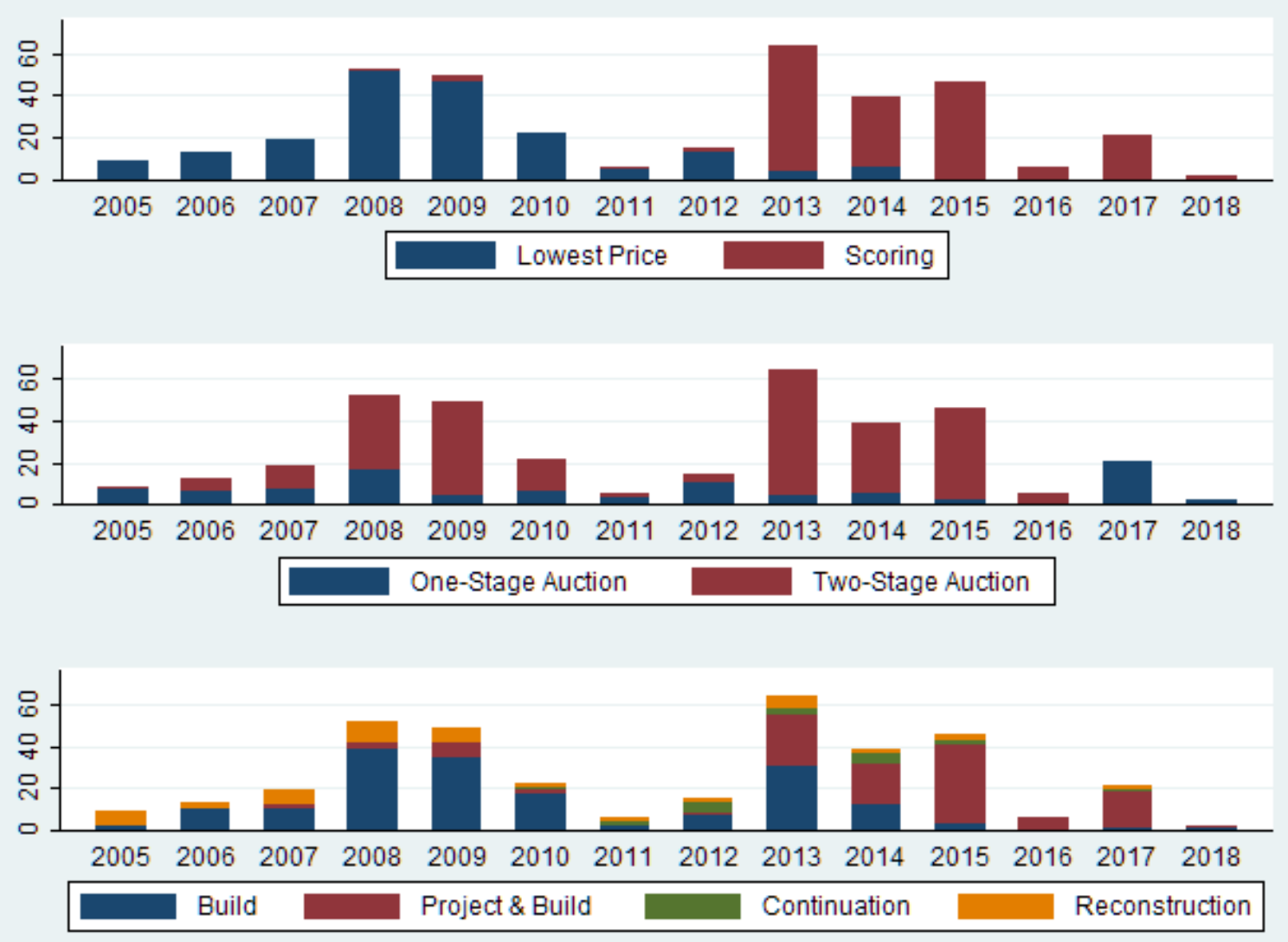

As it turns out, bidders always compete in prices. Although a scoring auction puts substantial weight on quality, there is negligible variance in the quality scores. In our sample, $95.7 \%$ of non-price scores are maximal and bidders, on average, reach $98.9 \%$ of the total non-price score. Hence, rankings are almost solely determined by monetary offers and it is unlikely that offering a low price and a high quality represents a trade-off for bidders. ${ }^{18}$

Figure 2 shows the average number of bidders per auction over years and the average number of subcontractors cooperating in a consortium with the leader. Although the competitiveness of auctions does not show a clear time trend, it is clear that the presence of consortia consisting of many firms diminished in the second half of the sample period. ${ }^{19}$

For the entire sample, $75.7 \%$ of all bids are submitted by firms with a foreign headquarter or firms owned by a foreign construction company. ${ }^{20}$ This share does not exhibit a significant time trend. Foreign firms are more successful and win $80.4 \%$ of all contracts. We can observe a similar pattern in the value of contracts, whose mean amounts to 317 million PLN for domestic and to 454 million PLN for foreign main contractors.

\footnotetext{
${ }^{18}$ Quality score and price relative to the lowest (winning) bid are not correlated at a $5 \%$ significance level.

${ }^{19}$ Zero subcontractors means that a given company submitted a bid on its own as a single firm. The figure does not take into account subcontracting by firms which are fully owned subsidiaries of a given leader.

${ }^{20} \mathrm{We}$ classify a firm as foreign if at least $51 \%$ is owned by foreign capital. Some firms changed their status within the sample period. For details, see Appendix D.
} 
Figure 2. Mean number of bids per auction and mean number of minor consortium members per bidder over years.

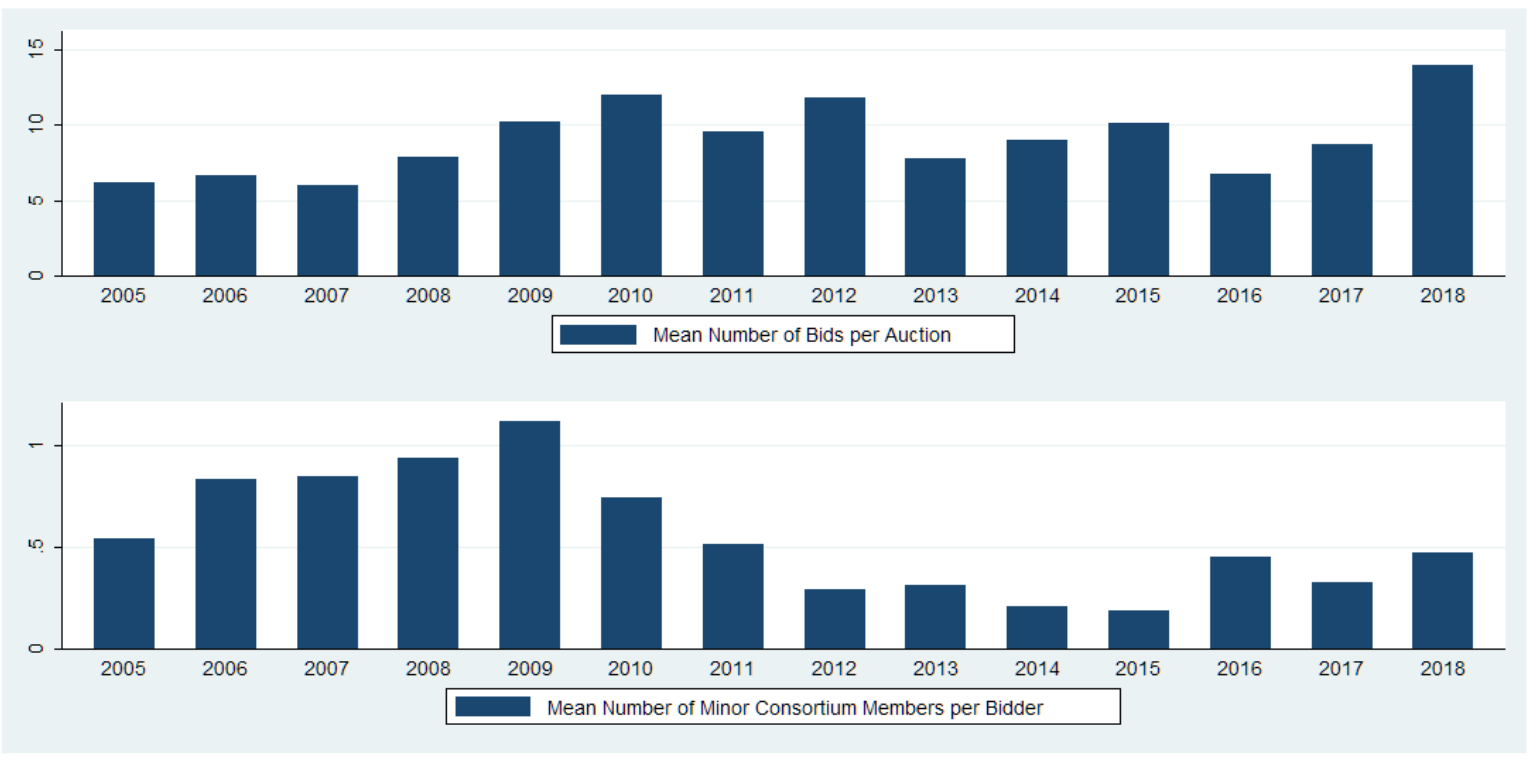

These differences result in a remarkable disparity in the total value of contracts as domestic companies have a mere $14.9 \%$ market share.

Measured by frequency, the market is dominated by a handful of dominant firms. A list of 20 most frequent bidders can be found in Appendix $D$. The frequency of bids is measured by the number of bids submitted as an individual firm or as a main consortium member. Firms are measured together with their subsidiaries, if such exist. In total, 20 largest bidders submitted more than $71 \%$ of all bids and won $77 \%$ of all contracts with a market share of $79 \% .{ }^{21}$

\subsection{Litigation}

The KIO database reveals that out of the 363 auctions, 100 feature some court appeals. Technically, the plaintiff in each case is a coalition of firms or their consortia, and the defendant is the procurement authority (GDDKiA). If a decision of the procurer is affirmed, by rejecting all appeals against it, the evaluation of the offers does not change. On the other hand, if an appeal is accepted, GDDKiA decisions are annulled and the procurer is obligated to reassess the offers and their ranking.

For these reasons, we distinguish two types of appeals. Type I, or simply 'a defensive appeal', refers to a motion that aims to change the procurer's decision by reversing the rejection of the plaintiff's offer. Alternatively, it is a complaint about a faulty auction procedure in general. Type II, or 'an offensive appeal', features a claim that another bidder's offer contains an error and it should be rejected. From all auctions, 54 were followed by Type I, and 60 were followed by Type II appeals. All auctions considered, 34 had more than one appeal and 14 of them exhibited both types. Out of 176 appeals, 56 were successful, meaning the success rate is only $32 \%$.

\footnotetext{
${ }^{21}$ This market concentration is slightly higher when compared to the Californian highway construction market data with a 73.4\% market share of the 20 largest firms, as evidenced by Bajari, Houghton, and Tadelis, 2014.
} 


\section{Theoretical Model}

We follow the footsteps of D. Levin and Smith, 1994 and use a dynamic auction model. A procurer announces a first-price sealed-bid auction for a single contract to $k$ risk-neutral and ex ante symmetric potential bidders, who may enter the competition. Then, after receiving signals about their types, which are described in detail in the next paragraph, all $k$ bidders make decisions on entry. The number of entering firms is publicly disclosed before making bids and is denoted by $n$. Bidders who decide to enter the competition simultaneously make bids. The submitter of the lowest offer wins and pays an amount equal to its bid. This framework models the two-stage scheme, which is most often used in GDDKiA auctions.

\subsection{Bidding Model with Screening}

Each bidder, before making a decision on entry, receives an independently drawn signal $c_{i}$ about its costs. The signal is drawn from a distribution described by a twice continuously differentiable cumulative density function $F_{c}(c)$ with a finite support $[\underline{c}, \bar{c}]$. Unlike Samuelson, 1985, we allow for non-uniform entry cost $e_{i}$, which captures a firm's ability to undertake new projects. Intuitively, the value is heterogeneous among firms due to their size as large firms enjoy smaller entry costs because of economies of scale. The costs are drawn from a distribution described by its twice continuously differentiable cumulative density function $F_{e}(e)$ with a finite support $[\underline{e}, \bar{e}]$. We assume that the construction $\operatorname{cost} c_{i}$ and entry cost $e_{i}$ are independently drawn across all bidders and firm $i$ is fully characterized by its type $\left(c_{i}, e_{i}\right)$. The cumulative distribution function $F_{c, e}(c, e)$ is assumed to be twice continuously differentiable.

In the absence of screening, bidder $i$ maximizes its expected profit in the bidding phase:

$$
\max _{b_{i}} \mathbb{E}\left[\pi\left(b_{i}, b_{-i}, c_{i}\right)\right]=\left(b_{i}-c_{i}\right) \cdot \operatorname{Pr}\left\{b_{i}=b_{1}\right\},
$$

where $b_{i}$ is bidder $i$ 's bid, $b_{-i}$ is the set of all other bids, $c_{i}$ is $i$ 's cost signal, and $b_{1}$ denotes the lowest bid. Firm $i$ enters the auction if the corresponding expected profit is larger than the entry costs, i.e., $\max _{b_{i}} \mathbb{E}\left[\pi\left(b_{i}, b_{-i}, c_{i}\right)\right] \geq e_{i}$. In the case of no participation a bidder receives its outside option that is normalized to 0 .

Proposition 1. For any $c_{i}$, the equilibrium bid of a firm, denoted as $b^{*}\left(c_{i}\right)$, is a decreasing function of the number of entering bidders $n$ and of the number of potential entrants $k$.

Proof. See Appendix E.

We extend the model by assuming that the procurer implements a screening system that rejects bids with a given probability. For simplicity, we allow for the possible rejection of the most competitive bid only, as it is unlikely in practice that the two lowest bids are both simultaneously rejected in the same auction.

The probability of rejection, conditional on submitting the lowest bid, is a function of entry cost $e_{i}$, expressed as a non-decreasing, twice-continuously differentiable function $\alpha\left(e_{i}\right) \geq 0$. The intuition behind this is that firms which are able to carry out more projects (i.e., the ones with low $e_{i}$ ) are also the ones with better legal and administrative teams, which are also responsible for preparing offers and defending them in courts. 
Function $\alpha\left(e_{i}\right)$ captures the disadvantage of small firms. Its steep slope signals a more pronounced difference between firms of different entry costs. On the other hand, a constant $\alpha\left(e_{i}\right)$ would mean that legal strength has no influence on screening and the subsequent litigation. The extreme case $\alpha\left(e_{i}\right)=0$ describes a situation with no screening, when all bids are accepted, which corresponds to our baseline model. Conditional on entering, the objective function of the firm becomes:

$$
\max _{b_{i}} \mathbb{E}\left[\pi\left(b_{i}, b_{-i}, c_{i}, \alpha\left(e_{i}\right)\right)\right]=\left(\left(1-\alpha\left(e_{i}\right)\right) \cdot \operatorname{Pr}\left\{b_{i}=b_{1}\right\}+\alpha\left(e_{1}\right) \cdot \operatorname{Pr}\left\{b_{i}=b_{2}\right\}\right) \cdot\left(b_{i}-c_{i}\right),
$$

where $e_{1}$ refers to the entry cost of the bidder with the lowest offer. Equation (2) is different from (1) in two aspects. First, a firm may be rejected if it is ranked first. Second, a firm that is ranked second may win if the first-ranked bidder is rejected. These terms depend on the specification of the screening function $\alpha\left(e_{i}\right)$, which can be freely set by the procurer, respecting the assumptions above. Entry takes place if the expected payoff covers the entry cost, $\max _{b_{i}} \mathbb{E}\left[\pi\left(b_{i}, b_{-i}, c_{i}, \alpha\left(e_{i}\right)\right)\right] \geq e_{i}$.

Proposition 2. For a constant $\alpha\left(e_{i}\right)=\alpha$, the marginal effect of $\alpha$ on entry is negative for firms with sufficiently low costs $c_{i}$, and positive for firms with sufficiently high costs $c_{i}$.

\section{Proof. See Appendix E.}

A higher uniform rejection rate may not favor more competitive firms as a lower probability of winning with the most competitive bid has a stronger effect on the expected payoff than a higher probability of winning with submitting the second lowest bid. In terms of Proposition 2, a higher entry among firms with a higher cost $c_{i}$ can be achieved with a less lenient screening system that does not discriminate between firm types. Intuitively, if rejections occur more often for firms with higher barriers to entry (i.e., higher values of $e_{i}$ ), we can observe two effects. Differentiated rejection rates imply that favored efficient firms may enjoy a higher entry rate but this may be compensated by a larger drop in entry of firms that have higher entry cost $e_{i}$. The role of high overall entry is to increase the competition level in the spirit of Proposition 1. Lower entry may, in turn, imply less competition and higher bids and, consequently, a higher ex ante expected price for the auctioneer. As the effect of the screening function is not uniform for firms with different levels of barriers to entry, it is yet to be tested which effect dominates.

\subsection{Model Predictions}

The main prediction of the model is that the firm size positively affects the chance of a bid being accepted.

Hypothesis 1. Small firms have higher rejection rates, $\alpha^{\prime}\left(e_{i}\right)>0$.

Hypothesis 1 can be evaluated by comparing firms by size. As actual firm size is a poor predictor of available resources and it is correlated with entry, we use three different measures as a proxy for $e_{i}$ : number of submitted bids, backlog, and capacity.

The second hypotheses concerns the strategic effects of screening and is a direct test of Proposition 2.

Hypothesis 2. The rejection rate $\alpha\left(e_{i}\right)$ has a negative effect on entry. 
If both Hypothesis 1 and 2 hold, screening has a negative effect on the entry of small firms.

\section{Empirical Model of Bidding}

In the two forthcoming sections, we build up empirical models that confront the predictions of the theoretical model of Section 3 against the data. As is standard in the literature, in Subsection 4.1, we start analyzing bidding empirically using OLS models. These are in turn extended in Subsection 4.2 by the use of instrumental variable techniques.

Moreover, we assume that bidders form ex ante beliefs on screening outcomes. The expected probability of rejection is estimated in Subsection 5.1 with a logit model that controls for firm size measures and major auction characteristics. Then, a 2SLS loglinear bidding model of Section 4.2 is augmented in Subsection 5.2 with this estimated rejection probability. Furthermore, using the same variable, we construct a binary model that gives an estimate of the effect of screening on entry. Finally, in Subsection 5.3 we assess the impact of screening on improving the road quality.

\subsection{OLS Model of Bidding}

One of the main points of interest is the effect of competition on bids. As Proposition 1 yields a prediction on bidding strategy and it implies that entry puts competitive pressure on bids, we estimate a corresponding empirical bidding model using OLS. Heterogeneity in the number of auction stages may provide a different competitive setting as one-stage auctions lack an official feedback on the number of eligible bidders. It is doubtful, however, that there is no information leakage at all in the first-stage auction. We can presume then that there is some interim information about participation before bid submission. In the two-stage format, bidders know the identity of their potential competitors as it is disclosed before bidding. Hence, we test for heterogeneity in the information structure between auction formats. We estimate the model: ${ }^{22}$

$$
\log \left(b_{i}\right)=\beta_{0}+\beta_{1} \cdot \log (n)+\beta_{2} \cdot \log (n) \times O S+\beta \cdot X+\epsilon,
$$

where $b_{i}$ stands for a bid, $n$ is the number of bidders, $X$ is the vector of all other covariates including contract type, road characteristics, and regional dummies. Variable ' $O S$ ' stands for 'one stage' binary indicator. Testing the statistical significance of $\beta_{2}$ implies a two-sided test of the stage number effect. That is, our model allows us to test whether first-stage auctions create a different information setting for bidders.

Following Porter and Zona, 1993, we calculate backlog as a measure of the bidders' used capacities. The measure serves as a proxy for whether a firm is facing capacity constraints. It is constructed as follows. The variable takes all the ongoing projects of a bidder at the point of bidding in a given auction, assuming the capacities are used in a uniform fashion. Backlog is constructed on each day of the sample time period by summing this per-day value of all the running projects of a given firm. The relevant period runs from signing a contract to the date of the opening of a road. As soon as the firm's projects are completed, the backlog of a firm goes to zero, unless new contracts are won.

\footnotetext{
${ }^{22} \mathrm{All}$ logs in the text denote natural logarithms.
} 
For all finished contracts in our database, both the starting time of the contract and its completion date are available. At the time of observation, 117 roads in our sample, out of all 363 contracted road segments, were still under construction. Their completion dates are imputed by performing a maximum likelihood estimation with a parametric regression survival-time model assuming Weibull distribution and conditioning on the technical characteristics of roads. ${ }^{23}$

Table 2 lists the OLS regression estimates of the model specified in Equation 3 in columns (1) and (2). The coefficients on the number of bidders in both models are negative, suggesting that higher competition reduces bids, but they are not significant at a $5 \%$ level. However, the number of bidders in a one-stage auction exercises a competitive pressure on bids and the effect is significant at the $0.1 \%$ level in the fully specified model in column (2). Thus, bidders form noisy beliefs about entry possibly by receiving some signals before submitting bids.

Our model also suggests that using scoring as the awarding mechanism has no significant effect on bids. We approximate the awarding mechanism with the weight on price, which assumes a value between 0.6 and 0.95 in scoring and 1 in lowest-price auctions. The lack of significance is likely related to the quality requirements we described in Subsection 2.2. Although quality standards are scored, a cap is applied to their values, which is easy to reach and there is very low variance in the quality score as nearly all firms submit the best possible quality and/or completion times. Effectively, bidders in fact compete only in prices.

We find that generally accepted results about the effect of capacities on bidding do not hold in an open market. ${ }^{24}$ The sign of the estimated coefficient for backlog is negative and significant at a $5 \%$ level in the model in column (2). A potential underlying reason behind the low value and the surprising sign of the estimate is that the biggest foreign firms have a small foothold in the local market compared to their total size. ${ }^{25}$ On the other hand, the backlog of many small firms is mostly zero. Lastly, our measure of backlog is an imperfect proxy for the overall capacity constraints of firms as most, if not all, companies are also involved in other construction projects, e.g., local roads, railways or apartments, which constitute a substantial portion of their domestic portfolio.

Interestingly, the deposit requirements for the winner do not alter bids as the coefficient estimates for Deposit II fail to be significant at a $5 \%$ level in either of the specifications. Also, we find no decisive evidence that firms from different countries bid differently. Foreign firms submit higher bids than domestic players, but the effect is not robust as the coefficient is significant at a $5 \%$ level only in model (2).

\subsection{SLS Model of Bidding}

A concern with using the OLS method is that entry may be linked to unobserved auction characteristics. Such unobserved characteristics may be important factors for road construction, for example, ground stability in the road location or a required non-standard construction material or technique. This may create an endogeneity bias and distort our results.

\footnotetext{
${ }^{23}$ Jofre-Bonet and Pesendorfer, 2003 use planned completion dates for contracts that did not finish by the end of the sample period. However, this variable is not available in our sample. The survival-time model uses the same list of road characteristics as models in Table 2.

${ }^{24}$ Jofre-Bonet and Pesendorfer, 2003 show that short-run capacity constraints have profound negative effects on entry and positive effects on bidding.

${ }^{25}$ For example, Strabag's total annual revenue in 2016 was 12 billion EUR (54 billion PLN), which exceeds its maximum backlog of slightly below 1 billion EUR (4.11 billion PLN) substantially (www . strabag . com).
} 
Table 2. OLS and 2SLS estimates on bids.

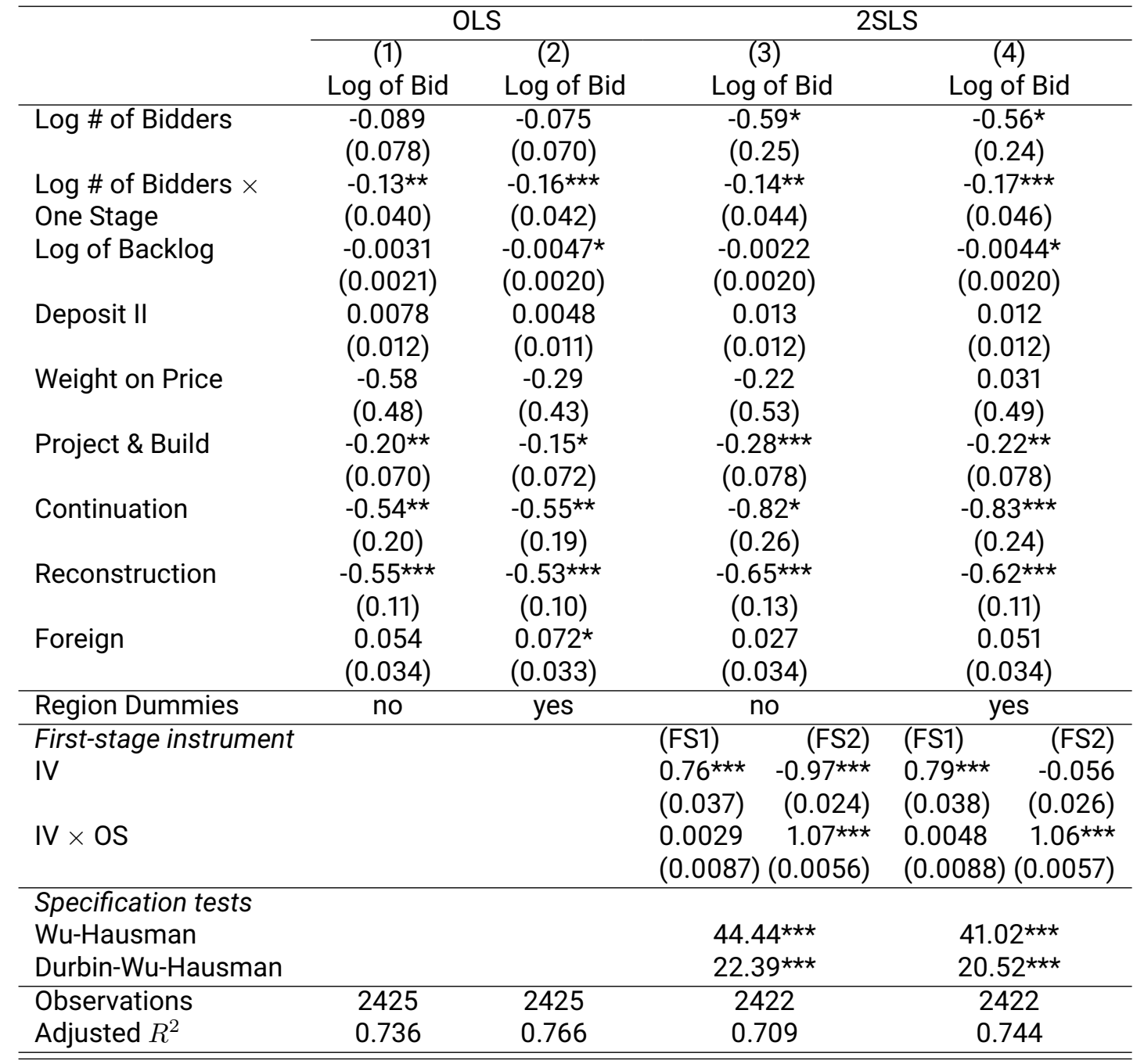

Standard errors clustered by auction. ${ }^{*} p<0.05,{ }^{\star \star} p<0.01,{ }^{\star \star \star} p<0.001$.

A standard technique used in the literature is to instrument the number of bidders with the number of companies registered in the first stage of an auction. ${ }^{26}$ As firms do not know the project characteristics, this is considered a valid instrument (De Silva et al., 2008). Unfortunately, this number is not universally available in our sample. As an alternative, we use the average number of bidders in auctions in the preceding 365 days, excluding same-day auctions in order to mitigate the problem of endogeneity due to potentially related contracts. ${ }^{27}$

It is not possible to verify the exogeneity of the instrument directly, but it is plausible for the following reasons. It is unlikely that entry would be affected by any characteristics of previous auctions as, conditional on entry, the equilibrium strategy of a firm may only be influenced by its own and other firms' costs, which pertain to a given auction. A potential concern regarding the exclusion restriction is that the instrument is correlated with an unobserved market-related variance. This is, however, unlikely. When firms submit their bids, only current costs, driven by the current market situation, are taken into account. Even if the opposite

\footnotetext{
${ }^{26}$ The literature refers to them as plan holders.

${ }^{27}$ The procurer divides some roads into separate segments and announces auctions for each segment separately on the same day. These contracts may share similar characteristics.
} 
were true, the time lag of the information used for the instrument is rather limited. It is improbable that fundamental changes occur in the market setting within one year.

The IV model is estimated using the two-stage least squares,

$$
\begin{gathered}
\log (n)=\pi_{0}+\pi_{1} \cdot I V+\pi_{2} \cdot I V \times O S+\pi_{3} \cdot X+\epsilon, \\
\log (n) \times O S=\pi_{0}+\pi_{1} \cdot I V+\pi_{2} \cdot I V \times O S+\pi_{3} \cdot X+\epsilon,
\end{gathered}
$$

where $I V$ stands for the instrumental variable, $O S$ is the one-stage auction indicator and $X$ is the set of technical characteristics. The proposed instruments turn out to be strong, evidenced by the significant coefficients in the first-stage equations in Table 2. The coefficients of the first-stage equations suggest that our instruments are strongly correlated with the number of bidders and the respective interaction term in the auction. This is consistent with our claim above that the market is stable and entry is not affected erratically by short-term market shocks.

The use of instrumental variables is justified, which is confirmed by the Wu-Hausman F-test as well as Durbin-Wu-Hausman test statistics as they are all significant at a $0.1 \%$ level. As the null hypotheses, assuming no statistical differences between OLS and 2SLS results, are rejected, the OLS estimates are not consistent.

The coefficient estimates of the log number of bidders are negative in both models (3) and (4), meaning that higher competition translates into lower highway prices. Estimates based on the instrumental variable approach predict much higher competitive pressure than OLS estimates and, contrary to the OLS results, are significant at the $5 \%$ level in both models. The coefficients on interaction term of competition in one-stage auctions do not change substantially in comparison to the OLS estimates.

Similarly, as in models (1) and (2), the 2SLS estimates indicate that the impact of the auction mechanism on bidding is not significant at a $5 \%$ level. Moreover, firm characteristics including backlog and foreign status do not affect their bidding strategies. Again, deposit requirements fail to have an impact on bids as none of the coefficients are significant.

\section{Screening and Entry}

To formalize the effect of screening in auctions, we extend the non-structural model we introduced in the preceding section. Screening can result in the rejection of bids and bidders anticipate this. The rejection rate may vary between firms of different size. If this is in favor of firms with smaller barrier-to-entry, it adversely affects competition and increases prices compared to a mechanism with an equal interim rejection rate among bidders. Success in screening and litigation is strongly related as both indicate a firm's ability to avoid rejection. Hence, we handle these two factors together.

\subsection{Screening and Rejection Probability}

In what follows, we explore empirically the underlying reasons behind bid rejections and test Hypothesis 1. In the sample, 454 offers have been rejected, which accounts for $15.77 \%$ of all bids. There is a sizable difference between the rejection rate of foreign (14.36\%) and domestic firms (20.14\%). The contrast is even 
more pronounced if we compare the 20 most frequent bidders (13.3\%) with other firms $(21.8 \%)$. In what follows we explore this disparity and its implications. ${ }^{28}$

Unfortunately, the data lacks full information on the bids of rejected tenders and always includes only the identity of these bidders. ${ }^{29}$ However, it is reasonable to assume that Type II appeals (i.e., 'offensive appeals') are directed mainly against low bids. As a way of testing this, we include competitiveness as a covariate in our model. The variable is constructed in the following way. A bid of a given company $b_{i}$ is divided by the winning bid $b_{1}$ in an auction, giving a relative bid $b_{i} / b_{1}$. This value is 1 for a winning bid and larger than 1 for everyone else. The mean of this variable is calculated for each firm across all auctions in which a company took part and submitted an accepted offer. The value of this firm-specific and time-invariant variable is always at least 1 (it would be equal to 1 if a firm had won all auctions in which it participated) and higher values correspond to less competitive bids on average. ${ }^{30}$

The probability of being rejected is estimated in a binary logit model as follows:

$$
\operatorname{Pr}(\text { Reject })=\frac{\exp \left(\beta_{0}+\beta_{1} \cdot \text { Competitiveness }+\beta_{2} \cdot \text { Size }+\beta \cdot X\right)}{1+\exp \left(\beta_{0}+\beta_{1} \cdot \text { Competitiveness }+\beta_{2} \cdot \text { Size }+\beta \cdot X\right)}
$$

where the variable Size captures the ability of a firm to undertake new projects and Competitiveness is the measure defined above. In the absence of entry costs, we model barriers to entry by using three different proxy variables: the number of all submitted bids in the sample period, backlog, and capacity.

The purpose of this step of our estimation strategy is to directly test Hypothesis 1. Table 3 reveals important patterns regarding the screening process and confirms Hypothesis 1 . The first is that smaller firms face substantially higher rejection rates. As we can see, the effect of firm size, for all three measures we use, is significant at a $0.1 \%$ level. It appears that the effect of competitiveness has no significant effect on screening outcomes.

Interestingly, the origin of bidders does not appear to be significant in any of the models. When controlled for size, foreign firms have an equal chance of failing screening as do domestic bidders. This may be surprising as domestic entities may have superior knowledge of the legal as well as the administrative system. A straightforward explanation for this result is that most foreign bidders have a well-established presence in the market and work with a permanent local team, hence, they suffer no disadvantage.

The models also control for the number and type of appeals. Type I is in favor of the plaintiffs' bids, while Type II claims a rightful rejection of competitors. The coefficient estimates for Type II appeals are positive and significant at the $5 \%$ level in all specifications. Hence, the model demonstrates that going to court in order to make competitors fail screening is an effective tool and has a negative overall effect on the number of accepted offers. However, the effect of the number of Type I ('defensive') appeals on the final outcomes is not different from zero at a $5 \%$ significance level.

\footnotetext{
${ }^{28} \mathrm{As}$ no data is available on the first-stage registrations in two-stage auctions, building a model including first-stage rejections is not possible. Consequently, the estimated rejection probability should be interpreted as an estimate of a chance of being rejected after submitting a bid in the second stage. First-stage participation is considerably cheaper, hence, omitting the impact of rejection probabilities on first-stage decisions is unlikely to bias estimates.

${ }^{29}$ Only about $60 \%$ of all rejected bids are available.

${ }^{30}$ We run regressions identical to that in Table 3 , in which competitiveness is replaced by the bid, if only it is observable. In all three models, the coefficient of the bid size is negative and significant at a $10 \%$, but not significant at a $5 \%$ level. These results are consistent with that the procurer does reject abnormally low offers, but screening is mainly driven by other criteria. However, these estimates may be biased as there is no clear indication as to why the rejected bids are missing in some auctions in our data.
} 
Overall, our estimates strongly support Hypothesis 1. Large firms enjoy lower rejection rates, while small firms suffer the opposite conjecture. The effect of competitiveness is clearly not significant.

Table 3. Logit model on bid rejection.

\begin{tabular}{lccc}
\hline \hline & $(1)$ & $(2)$ & $(3)$ \\
& Rejected & Rejected & 0.0049 \\
Competitiveness & 0.27 & -0.25 & $(0.74)$ \\
Log of Backlog & $(0.70)$ & $(0.69)$ & \\
& $-0.026^{* *}$ & & \\
Log of \# of Bids & $(0.0093)$ & & $-0.038^{* *}$ \\
Log of Capacity & & $-0.21^{* * *}$ & $(0.014)$ \\
Foreign & & $(0.045)$ & -0.25 \\
& & & $(0.14)$ \\
Number of Type I Appeals & -0.25 & -0.13 & 0.10 \\
Number of Type II Appeals & $(0.13)$ & $(0.14)$ & $(0.075)$ \\
& 0.11 & 0.091 & $0.18^{*}$ \\
Two Stages & $(0.075)$ & $(0.075)$ & $(0.080)$ \\
& $0.18^{*}$ & $0.18^{*}$ & $-0.39^{* *}$ \\
Project \& Build & $(0.081)$ & $(0.080)$ & $(0.13)$ \\
& $-0.42^{* * *}$ & $-0.36^{* *}$ & $0.66^{* * *}$ \\
Continuation & $(0.13)$ & $(0.13)$ & $(0.12)$ \\
& $0.67^{* * *}$ & $0.70^{* * *}$ & $-1.40^{* *}$ \\
Reconstruction & $(0.12)$ & $(0.12)$ & $(0.53)$ \\
Constant & $-1.40^{* *}$ & $-1.35^{*}$ & $-0.49^{*}$ \\
& $(0.54)$ & $(0.54)$ & $(0.20)$ \\
Observations & $-0.52^{*}$ & $-0.50^{*}$ & -1.03 \\
\hline \hline & $(0.20)$ & $(0.21)$ & $(0.95)$ \\
\hline & -1.59 & -0.50 & 2856 \\
\hline
\end{tabular}

Robust standard errors in parenthesis. ${ }^{*} p<0.05,{ }^{* *} p<0.01,{ }^{* * *} p<0.001$. Monetary values are expressed in 1 million PLN (2018 prices).

\subsection{Bidding and Entry with Beliefs About Rejection}

As Hypothesis 1 holds, we can test Hypothesis 2, and the overall competitive effect of screening, assuming that bidders form a rational belief regarding their probability of being rejected. That is, we test whether these beliefs have an effect on bidding and entry patterns. The estimation strategy is executed in two steps, addressing bidding and entry separately.

We re-estimate our bidding model with the estimated rejection probabilities as they may influence bids. We do so using fitted values from models (2) and (3) of Table 3. The estimated specifications are identical to those of Table 2, except for the fitted rejection probability as an additional regressor.

Table 4 shows that the coefficient estimate of the probability of rejection is positive and significant at a $5 \%$ level. We interpret the positive effect of the anticipated rejection rate as follows. Conditional on entry, firms with lower chances of having their offers not rejected bid less aggressively, so that they can get a 
substantial profit if they win. The marginal benefit from aggressive bidding does not substantially increase the chance of winning, but decreases the margin.

The other coefficient estimates of interest are similar to that of Table 2. The fully specified 2SLS model confirms that there is a significant competitive pressure on bids, whose effect is augmented in the onestage auctions.

Table 4. 2SLS estimates on bids with rejection probabilities.

\begin{tabular}{|c|c|c|c|c|}
\hline & \multicolumn{4}{|c|}{ 2SLS } \\
\hline & (1) & (2) & (3) & (4) \\
\hline & Log of Bid & Log of Bid & Log of Bid & Log of Bid \\
\hline \multirow{2}{*}{ Log of \# of Bidders } & $-0.62^{\star}$ & $-0.57 *$ & $-0.62^{\star}$ & $-0.58^{*}$ \\
\hline & $(0.25)$ & $(0.24)$ & $(0.26)$ & $(0.25)$ \\
\hline Log of \# of Bidders $\times$ & $-0.17 * \star \star \star$ & 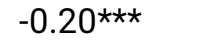 & $-0.16 * \star \star$ & 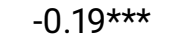 \\
\hline One Stage & $(0.047)$ & $(0.048)$ & $(0.046)$ & $(0.047)$ \\
\hline Estimated Prob. of & $1.65^{\star \star}$ & $1.89 \star \star$ & $1.08^{*}$ & $1.21^{\star \star}$ \\
\hline Rejection & $(0.63)$ & $(0.61)$ & $(0.45)$ & $(0.44)$ \\
\hline \multirow[t]{2}{*}{ Log of Backlog } & 0.00012 & -0.0018 & 0.00042 & -0.0015 \\
\hline & $(0.0020)$ & $(0.0020)$ & $(0.0021)$ & $(0.0020)$ \\
\hline \multirow[t]{2}{*}{ Deposit II } & 0.013 & 0.012 & 0.014 & 0.012 \\
\hline & $(0.012)$ & $(0.012)$ & $(0.012)$ & $(0.012)$ \\
\hline \multirow[t]{2}{*}{ Weight on Price } & -0.19 & 0.062 & -0.22 & 0.034 \\
\hline & $(0.54)$ & $(0.49)$ & $(0.54)$ & $(0.49)$ \\
\hline \multirow{2}{*}{ Project \& Build } & $-0.42^{\star \star \star}$ & $-0.37 \star \star \star$ & $-0.38 * \star \star$ & $-0.32^{\star \star}$ \\
\hline & $(0.10)$ & $(0.10)$ & $(0.098)$ & $(0.098)$ \\
\hline \multirow[t]{2}{*}{ Continuation } & $-0.67 \star \star$ & $-0.65^{\star \star}$ & $-0.73^{\star \star}$ & $-0.73^{\star \star}$ \\
\hline & $(0.26)$ & $(0.24)$ & $(0.25)$ & $(0.24)$ \\
\hline \multirow[t]{2}{*}{ Reconstruction } & $-0.58^{\star \star \star}$ & $-0.54^{\star \star \star \star}$ & $-0.61^{\star \star \star}$ & $-0.58^{\star \star \star}$ \\
\hline & $(0.13)$ & $(0.11)$ & $(0.13)$ & $(0.11)$ \\
\hline \multirow[t]{2}{*}{ Foreign } & $0.097 \star$ & $0.13^{\star \star}$ & 0.068 & $0.097 \star$ \\
\hline & $(0.043)$ & $(0.042)$ & $(0.039)$ & $(0.038)$ \\
\hline Region Dummies & No & Yes & No & Yes \\
\hline Size is Measured in & Capacity & Capacity & \# of Bids & \# of Bids \\
\hline \multicolumn{5}{|l|}{ Specification tests } \\
\hline Wu-Hausman & 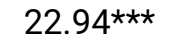 & 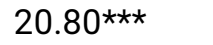 & $22.38 * \star \star *$ & $20.62^{\star \star \star}$ \\
\hline Durbin-Wu-Hausman & $45.53^{\star \star \star}$ & 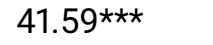 & $44.45^{\star \star \star}$ & $41.23^{\star \star \star}$ \\
\hline Observations & 2422 & 2422 & 2422 & 2422 \\
\hline Adjusted $R^{2}$ & 0.707 & 0.744 & 0.706 & 0.742 \\
\hline
\end{tabular}

Standard errors clustered by auction. ${ }^{*} p<0.05,{ }^{* \star} p<0.01,{ }^{\star \star \star} p<0.001$.

Our findings suggest that screening directly affects bidding as the estimated probability of rejection increases the submitted offers. However, another channel deserves our attention. As the estimates suggest, entry has a profound role in shaping bidding strategies. That is, if the prospect of being rejected discourages entry, bids are indirectly affected by bidders facing a smaller number of competitors.

In the sample, 135 firms submit at least one accepted bid either individually or as a main consortium member. In each case, we estimate the effect of the estimated rejection rate on the probability of entry. In terms of Hypothesis 2, if a firm expects a higher rejection rate, the probability of winning is lower, and hence, entry is less likely.

Table 5 shows estimates of alternative entry models that include the estimated rejection probability from the respective models of Table 3. The unit of observation corresponds to a bidder in a certain auction. 
Table 5. Logit model on entry.

\begin{tabular}{lcccc}
\hline \hline & $(1)$ & $(2)$ & $(3)$ & $(4)$ \\
& Entry & Entry & Entry & Entry \\
\hline Estimated Prob. of Rejection & $-25.0^{* * *}$ & $-6.66^{* *}$ & $-28.6^{* * *}$ & $-25.9^{* * *}$ \\
& $(2.46)$ & $(2.46)$ & $(2.62)$ & $(4.88)$ \\
Two Stages & $0.49^{* * *}$ & $0.25^{* * *}$ & $0.74^{* * *}$ & $0.70^{* * *}$ \\
& $(0.080)$ & $(0.071)$ & $(0.084)$ & $(0.10)$ \\
Deposit I & 2.56 & 7.83 & 2.91 & 7.07 \\
& $(4.81)$ & $(5.29)$ & $(5.31)$ & $(5.62)$ \\
Deposit II & 0.0074 & 0.0034 & 0.0092 & 0.012 \\
& $(0.0090)$ & $(0.0097)$ & $(0.0099)$ & $(0.011)$ \\
Project \& Build & $0.26^{* *}$ & -0.060 & $0.40^{* * *}$ & $0.33^{* *}$ \\
& $(0.083)$ & $(0.090)$ & $(0.091)$ & $(0.13)$ \\
Continuation & $-4.31^{* * *}$ & $-1.50^{* * *}$ & $-4.82^{* * *}$ & $-3.99^{* * *}$ \\
& $(0.35)$ & $(0.28)$ & $(0.27)$ & $(0.51)$ \\
Reconstruction & $-1.24^{* * *}$ & $-0.54^{* * *}$ & $-1.40^{* * *}$ & $-1.28^{* * *}$ \\
& $(0.11)$ & $(0.11)$ & $(0.098)$ & $(0.16)$ \\
Foreign & 0.21 & $0.62^{*}$ & 0.066 & 0.15 \\
& $(0.25)$ & $(0.26)$ & $(0.098)$ & $(0.11)$ \\
\hline Observations & 49005 & 16335 & 49005 & 16335 \\
\hline Size is Measured in: & Capacity & Capacity & $\#$ of Bids & $\#$ of Bids \\
Min. \# of Bids & 1 & 10 & 1 & 10 \\
\hline \hline
\end{tabular}

Standard errors clustered by bidder. ${ }^{*} p<0.05,{ }^{* *} p<0.01,{ }^{* * *} p<0.001$. Monetary values are expressed in 1 million PLN (2018 prices). All models include road characteristics, regional and year dummies. Road characteristics: log(length), road class, interaction terms between log(length) and class, number of junctions, dummy variables for bridge and tunnel, indicators for roads in minor and major urban areas, interaction term between log(length) and indicator for concrete road, monthly unemployment rate, and the log of the average number of warm days in the region.

The models differ in the measure of firm size. Furthermore, models (1) and (3) include all firms whereas models (2) and (4) exclude fringe bidders with less than 10 submitted bids in the sample period. The coefficient estimates clearly show that rejections have a profound negative effect on entry as all coefficients are significant at the $1 \%$ level. The size of the coefficients depends on the threshold size. With both measures of size, the effect of the estimated probability of rejection is smaller if fringe bidders, which form two-thirds of all bidders, are disregarded. This difference is intuitive: fringe bidders have high barriers to entry and react more strongly to negative incentives. Having only bidders of meaningful size implies a more homogeneous sample in this respect. Again, there is no conclusive evidence that the origins of firms have a strategic effect. Hence, the test results confirm that, controlling for size, foreign firms do not differ from domestic ones in their ability to undertake new projects.

None of the two deposit requirements affect entry. A plausible explanation is provided by their low values. Although one would expect a negative effect of the initial deposit, its mean value is merely $1.2 \%$ of the winning bid. The model suggests that firms are not liquidity constrained to the extent that such small deposits would deter them from submitting a bid.

Overall, the empirical evidence strongly supports Hypothesis 2. Given that screening affects small firms differently, the total effect of the screening policy on prices is positive. 


\subsection{Screening and Performance}

In order to assess the effectiveness of screening, we estimate its effect on the auction procedure and ex post performance. The outcome variables are defined as follows. The first is the time span between the starting date of an auction and the date of signing the contract, we refer to it as the duration of procedure. As road quality measures are not available in data, we use the duration of construction as a proxy for performance. $^{31}$

The administrative rules on screening did not substantially change in the sample period. However, there is a variance in the realized probability of rejection. Reflecting this, we create a measure for screening intensity by taking the share of rejected bids among all submitted ones in a given calendar year. Out of 363 roads in the sample, 117 are still under construction. As the data is right-censored, we perform a maximum likelihood estimation with a parametric survival model assuming Weibull distribution. As covariates, we use screening intensity, relevant administrative auction rules as well as technical road characteristics.

Models in Table 6 estimate the effect of screening intensity on the duration of both phases separately. The negative coefficient in all models indicate that, on average, higher intensity reduces the chance of either signing the contract or finishing the road. It means that we find no evidence that stricter screening results in a shorter delivery time.

Nevertheless, the coefficients in models (1) and (2) show that screening has no statistically significant effect on the completion of a road segment. That is, this performance measure does not vary in different levels of screening intensity. On the other hand, signing the contract suffers substantial delay as the corresponding coefficient is negative and significant at a $0.1 \%$ level in both models (3) and (4). This result is anticipated. Negative screening outcomes attract more complaints and appeals, hence, the final outcome is announced substantially later.

The estimates do not provide evidence on the usefulness of the screening procedure. However, one has to keep in mind that the effect of screening intensity may not be linear and the sample only includes observations for which screening was used. Therefore, the conclusion that lower-than-average screening intensity improves, or at least does not adversely affect, performance measures should be treated with some caution.

\footnotetext{
${ }^{31}$ Decarolis et al., 2018 use time and cost renegotiation as a proxy for quality, which is the time difference between the contracted and realized delivery. The former is, unfortunately, not available in the data. As the projects are relatively homogeneous and their characteristics are controlled for, we believe the estimates would be comparable.
} 


\begin{tabular}{lcccc}
\hline \hline & $(1)$ & $(2)$ & $(3)$ & $(4)$ \\
& $\begin{array}{c}\text { Duration of } \\
\text { Construction }\end{array}$ & $\begin{array}{c}\text { Duration of } \\
\text { Construction }\end{array}$ & $\begin{array}{c}\text { Duration of } \\
\text { Procedure }\end{array}$ & $\begin{array}{c}\text { Duration of } \\
\text { Procedure }\end{array}$ \\
\hline Screening Intensity & -2.63 & -3.47 & $-6.27^{* * *}$ & $-6.77^{* * *}$ \\
& $(1.81)$ & $(1.89)$ & $(0.91)$ & $(0.95)$ \\
Weight on Price & -2.24 & -1.50 & -1.52 & -0.85 \\
& $(2.35)$ & $(2.48)$ & $(0.96)$ & $(0.99)$ \\
Two Stages & $-1.14^{* * *}$ & $-0.96^{* * *}$ & $-1.35^{* * *}$ & $-1.51^{* * *}$ \\
& $(0.21)$ & $(0.23)$ & $(0.15)$ & $(0.18)$ \\
Build & $-0.44^{*}$ & $-0.75^{* * *}$ & -0.33 & $-0.41^{*}$ \\
& $(0.19)$ & $(0.21)$ & $(0.18)$ & $(0.20)$ \\
Project \& Build & $-0.84^{* *}$ & $-0.71^{*}$ & $-0.40^{*}$ & $-0.46^{*}$ \\
& $(0.31)$ & $(0.34)$ & $(0.21)$ & $(0.22)$ \\
Continuation & $0.81^{*}$ & $1.09^{* *}$ & 0.33 & 0.30 \\
& $(0.35)$ & $(0.40)$ & $(0.31)$ & $(0.32)$ \\
\hline Region Dummies & No & Yes & No & Yes \\
\hline Observations & 363 & 363 & 363 & 363 \\
\hline \hline
\end{tabular}

Standard errors in parentheses. ${ }^{*} p<0.05,{ }^{* *} p<0.01,{ }^{* * *} p<0.001$. All models include road characteristics: log(length), road class dummies, interaction terms between log(length) and class, number of junctions, dummy variables for bridge and tunnel, indicators for roads in minor and major urban areas, interaction term between log(length) and indicator for concrete road, monthly unemployment rate, and the log of the average number of warm days in the region.

\section{Discussion}

Myerson, 1981 shows that a level playing field may have adverse effects in auction markets. Although this idea is strongly endorsed in the literature, the primary focus is on ex ante measures supporting small- and medium-sized enterprises. This article contributes to this rich area of research by extending the scope to bid screening, which is a standard procedure in auctions, and showing that it has significant distortive effects that adversely affect small firms with high barriers to entry.

As a rejection can be anticipated, it has a negative effect on entry. Although larger firms may be less affected, smaller players experience a substantial increase of their barriers to entry. Hence, screening, augmented by court appeals, has strong competitive effects. We estimate that the number of bidders in an auction drops, the total effect on bids is positive, and the procurer suffers from inflated prices. We also show that domestic firms do not enjoy any advantage and the international dimension of competition does not appear to be relevant. Given that foreign tenderers are typically large enterprises, as small foreign players have a regional focus, the legal system results in an interesting paradox. Although domestic firms could be presumed to have a better understanding of domestic procurement law, large firms are rejected with a lower probability as they typically hire competent permanent legal teams.

The primary function of screening is to shield the procurer from risk and moral hazard problems. We find no evidence of benefits. With the use of a parametric regression survival time model, we estimate that completion time does not improve with more draconian qualification standards. However, stricter screening results in excessive delays in awarding the contract.

Screening in the form of ex post qualification may be augmented with some other measures. However, many of these are already used in the subject market. First-price sealed-bid auctions are widely endorsed 
in markets with limited liability (Wambach, 2006). While it is a widely endorsed method to combat limited liability, a possibility of splitting contracts even further is limited, in the context of highway construction, by the distance between road exits.

Depending on the development level of the domestic financial markets, screening may be replaced by other types of procedures. Standard solutions include letters of credit issued by banks or surety bonds issued by surety companies. These tools have multiple benefits over elaborate screening. They reduce transaction costs, mitigate extensive delays in contracting, and let the market price any potential risks. Surety insurance is a standardized product in public procurement in countries where insurance markets are sufficiently developed. ${ }^{32}$

In the absence of applicable insurance products, alternative measures may be imposed, such as average bid auctions (APA), in which the contract is awarded to the bid closest to the mean value of all bids. There is evidence that APA without screening attracts higher entry (Branzoli and Decarolis, 2015). However, this format may only be used to mitigate the problem of abnormally low offers and it does not cover the entire spectrum of issues connected with bankruptcy risk.

Screening may be augmented by offering public non-discriminative legal and administrative help to bidders. As firms with limited resources have higher alternative costs, they are more likely to accept support and their chance of passing screening improves. Such incentive schemes are appropriate in markets in which the legal framework does not endorse preferential programs for small and medium-sized enterprises.

\footnotetext{
${ }^{32}$ For example, insurance markets account for $12.8 \%$ of GDP in the United Kingdom, $6.3 \%$ in Germany, and $10.6 \%$ in France (OECD, 2017). In comparison, the same measure amounts to only $3 \%$ in Poland.
} 


\section{References}

Asker, John and Estelle Cantillon (2008). "Properties of scoring auctions." In: The RAND Journal of Economics vol. 39.1, p. 69-85.

- (2010). "Procurement when price and quality matter." In: The RAND Journal of Economics vol. 41.1, p. 1-34.

Athey, Susan, Dominic Coey, and Jonathan Levin (2013). "Set-asides and subsidies in auctions." In: American Economic Journal: Microeconomics vol. 5.1, p. 1-27.

Bajari, Patrick, Stephanie Houghton, and Steven Tadelis (2014). "Bidding for incomplete contracts: an empirical analysis of adaptation costs." In: American Economic Review vol. 104.4, p. $1288-1319$.

Börgers, Tilman (2015). An introduction to the theory of mechanism design. Oxford University Press.

Branzoli, Nicola and Francesco Decarolis (2015). "Entry and subcontracting in public procurement auctions." In: Management Science vol. 61.12, p. 2945-2962.

Coviello, Decio and Mario Mariniello (2014). "Publicity requirements in public procurement: evidence from a regression discontinuity design." In: Journal of Public Economics vol. 109, p. 76-100.

Coviello, Decio, Luigi Moretti, Giancarlo Spagnolo, and Paola Valbonesi (2017). "Court efficiency and procurement performance." In: The Scandinavian Journal of Economics vol. 120.3, p. 826-858.

De Silva, Dakshina G, Timothy Dunne, Anuruddha Kankanamge, and Georgia Kosmopoulou (2008). "The impact of public information on bidding in highway procurement auctions." In: European Economic Review vol. 52.1, p. 150-181.

De Silva, Dakshina G, Thomas D Jeitschko, and Georgia Kosmopoulou (2009). "Entry and bidding in common and private value auctions with an unknown number of rivals." In: Review of Industrial Organization vol. 35.1-2, p. 35-73.

Decarolis, Francesco (2014). "Awarding price, contract performance, and bids screening: evidence from procurement auctions." In: American Economic Journal: Applied Economics vol. 6.1, p. $108-132$.

Decarolis, Francesco, Leonardo M Giuffrida, Elisabetta Iossa, Vincenzo Mollisi, and Giancarlo Spagnolo (2018). Bureaucratic Competence and Procurement Outcomes. Tech. rep. National Bureau of Economic Research.

Dimitri, Nicola, Gustavo Piga, and Giancarlo Spagnolo (2006). Handbook of Procurement. Cambridge University Press.

Gillen, Philippe, Vitali Gretschko, and Alexander Rasch (2017). "Pre-auction or post-auction qualification?" In: Economic Theory Bulletin 5.2, pp. 139-150.

Goujard, Antoine (2016). "Improving transport and energy infrastructure investment in Poland." In: OECD Economic Department Working Papers 1302.

Gugler, Klaus, Michael Weichselbaumer, and Christine Zulehner (2015). "Competition in the economic crisis: analysis of procurement auctions." In: European Economic Review vol. 73, p. 35-57. 
Jofre-Bonet, Mireia and Martin Pesendorfer (2003). "Estimation of a dynamic auction game." In: Econometrica vol. 71.5, p. 1443-1489.

Krasnokutskaya, Elena and Katja Seim (2011). "Bid Preference Programs and Participation in Highway Procurement Auctions." In: The American Economic Review vol. 101.6, p. 26532686.

Levin, Dan and James L Smith (1994). "Equilibrium in auctions with entry." In: The American Economic Review, pp. 585-599.

Lewis, Gregory and Patrick Bajari (2014). "Moral hazard, incentive contracts, and risk: evidence from procurement." In: The Review of Economic Studies vol. 81.3, p. 1201-1228.

$\mathrm{Li}$, Tong and Xiaoyong Zheng (2009). "Entry and competition effects in first-price auctions: theory and evidence from procurement auctions." In: The Review of Economic Studies vol. 76.4, p. 1397-1429.

Milgrom, Paul (2004). Putting auction theory to work. Cambridge University Press.

Miller, Daniel P (2014). "Subcontracting and competitive bidding on incomplete procurement contracts." In: The RAND Journal of Economics vol. 45.4, p. 705-746.

Moretti, Luigi and Paola Valbonesi (2015). "Firms' qualifications and subcontracting in public procurement: an empirical investigation." In: The Journal of Law, Economics, and Organization 31.3, pp. 568-598.

Myerson, Roger B (1981). "Optimal auction design." In: Mathematics of Operations Research vol. 6.1, p. $58-73$.

OECD (2016). A Stocktaking report on MENA Public Procurement Systems. Tech. rep.

- (2017). OECD data on insurance spending. Online data. URL: https : / / data . oecd . org / insurance/insurance-spending.htm (visited on 05/01/2018).

Porter, R and D Zona (1993). "Detection of bid rigging in procurement auctions." In: Journal of Political Economy vol. 101.3, p. 518-538.

Samuelson, William F (1985). "Competitive bidding with entry costs." In: Economics Letters vol. 17.1-2, p. 53-57.

Wambach, Andreas R Engel-Achim (2006). "Public procurement under limited liability." In: Rivista di politica economica 96.1-4, p. 13. 


\section{Appendices}

\section{A Highway Construction Boom in Poland}

Figure 3 illustrates the progress in highway construction at the beginning and end of the sample period. Maps include A- and S-class roads. ${ }^{33}$
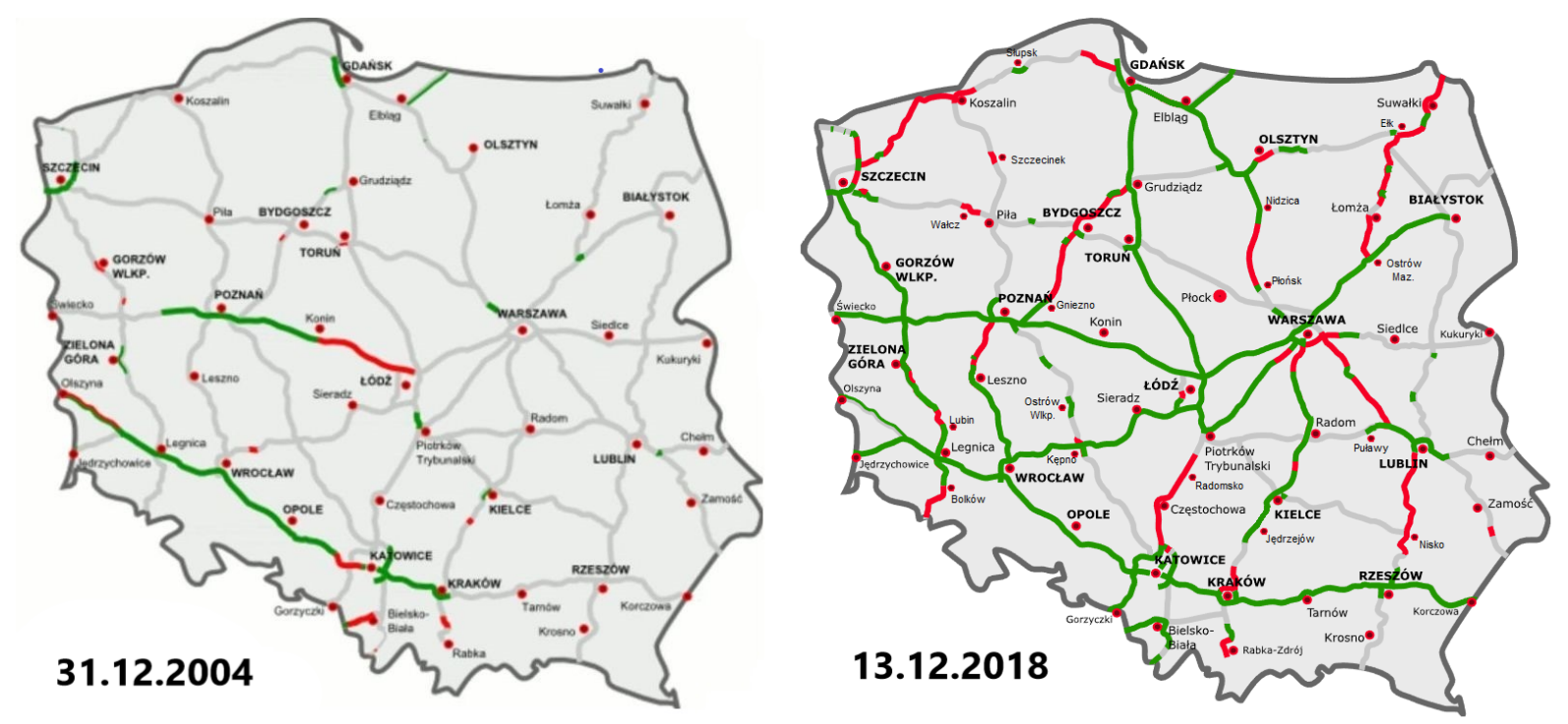

Figure 3. Network of A- and S-class highways in Poland in 2004 (left) and in 2018 (right). Green roads are opened, red roads are under construction, and gray segments are the planned. Source: https://pl.wikipedia.org/wiki/Autostrady_i_drogi_ekspresowe_w_Polsce

\section{B Data Sources}

We compiled data from the following main sources. Most data sources are available only in Polish and have been collected manually from separate documents.

1. Auction and Road Data: Summaries and documents on completed auctions are publicly available on the internet website of GDDKiA. ${ }^{34}$ The data is presented in a non-standardized format and is sometimes incomplete. In certain cases the missing data was provided on request. GDDKiA data contains names of bidders, their bids as well as auction characteristics (i.e. data on the auction mechanisms, number of auction stages, auction dates, dates when the contracts were signed and their types, etc.). Technical data on road characteristics and opening dates, etc., are collected from

\footnotetext{
${ }^{33}$ The maps exclude the G- and GP-class roads, which are most often built as new beltways around cities and towns.

${ }^{34}$ www.gddkia.gov.pl/en/27/about-directorate
} 
various sources, mainly from GDDKiA services, which provide data on road length, number of junctions, road types, tunnels, etc. Certain characteristics were supplemented using local newspapers, Google Maps or Google Views services if GDDKiA data was incomplete or not precise enough. This method was adopted to match junctions and regions (voivodships) with a given road contract and obtain construction material data.

2. Legal Data: Documentation of court rulings is publicly available at the website of $\mathrm{KIO}^{35}$ The site contains all KIO rulings from the Court's establishment in 2007. Standardized documentation includes all essential details of the legal process.

3. Macroeconomic Data: Data on unemployment and inflation indices are reported by the Central Statistical Office (Główny Urząd Statystyczny, GUS ${ }^{36}$ )

4. Firm Data: The capital ownership of firms was collected from the respective firms' websites.

\footnotetext{
${ }^{35}$ www.uzp.gov.pl/kio/english-version/home

${ }^{36}$ www.stat.gov.pl/en/
} 


\section{List of Variables}

Data on road characteristics and auctions

Auction Date

Backlog

Bid

Bridge

Capacity

Competitiveness

Concrete

Contract Date

Contract Type

Deposit 1

Deposit 2

Dissolution Date
Date when an auction is announced.

The total value of uncompleted contracts of a given company at the time of bidding.

Bid expressed in Polish złoty (PLN) in September 2018 prices. In September 2018, 1 PLN exchanged to about 0.23 EUR or 0.27 USD.

Dummy variable, equals 1 if there is a large bridge in a given road segment.

Maximum backlog in the whole period of the sample for a given firm.

The average relative bid (bid/winning bid) of a bidder for the entire sample.

Dummy variable, equals 1 if road is made of concrete, 0 if it is made of asphalt.

Date when a contract for a given road segment is signed.

Four contract dummies for 'Build', 'Project \& Build', 'Continuation', and 'Reconstruction' contract types.

Deposit paid by every participant of an auction.

Deposit paid by the winner of an auction after winning the contract.

Date when the contract is dissolved before road completion.

Duration of Construction Time between signing the contract and finishing the road.

Duration of Procedure Time between announcing the auction and signing the contract.

Foreign Leader Dummy variable, equals 1 if the main contractor is foreign or is at least $51 \%$ owned by a foreign firm.

Junctions A/S Number of grade-separated junctions with other A/S roads.

Junctions Other Number of grade-separated junctions with other roads of non-A/S-class.

Length Length of the road in $\mathrm{km}$. 
Minor

Number of Bids

Opening Date

Price Weight

Region

Road A/S/O

Scoring

Screening Intensity

Tunnel

Unemployment

Urban $0 / 1 / 2$

Vegetation

Data on appeals
Number of minor consortium members, equals 0 if a firm does not form a consortium and bids alone. Their identity is always provided.

Number of firms or consortia submitting bids in the auction.

Date when a given road is opened.

The percentage weight on price in the awarding criteria, equals 1 in a lowestprice auction and is smaller in scoring auctions. Its value is at least 0.6 in the data set.

Dummy variables for 16 highest-level administrative regions (voivodships) of Poland. Road-type classification dummies (A-class, S-class or other road type).

Dummy variable, equals 1 if the awarding mechanism is a scoring auction, no matter what weights are applied to quality and completion time.

Fraction of rejected bids among all submitted bids in a given calendar year.

Dummy variable, takes 1 if there is a tunnel in a given road segment.

Rate of registered unemployment in the auction announcement month.

Dummy variables corresponding to the area in which a road is located: uninhabited area, minor urban area, and major urban area, respectively.

Average number of vegetation days in a voivodship per year, i.e. days with the average temperature above 5 degrees Celsius.

Defendant Name of company whose offer is subjected to litigation. ${ }^{37}$

Plaintiff $\quad$ Name of plaintiff(s).

Type I Appeal Number of appeals in an auction related to the claim that a rejected tender is valid or that the procedure has general irregularities.

Type II Appeal Number of appeals in an auction which claim that a tender submitted by a party different from the plaintiff is invalid.

\footnotetext{
${ }^{37}$ Technically, GDDKiA is the defendant in every case.
} 


\section{List of Large Firms}

Table 7 lists the 20 largest firms ranked by the number of submitted bids as individual firms or as main consortium members. Subsidiaries are counted together with their owners. Since 2012, Hermann Kirchner's shares are 100\% owned by Strabag. Dragados owns Hochtief since 2011 and Pol-Aqua since 2009. Kobylarnia was acquired by Mirbud in 2010. Other subsidiaries have unbroken ownership over the sample period.

Table 7. List of 20 most frequent bidders.

\begin{tabular}{llllll} 
Name & bids & won & m. share & rej. rate & foreign \\
\hline Ferrovial \& Budimex \& M. Kraków & 321 & 60 & $17.7 \%$ & $4.5 \%$ & yes \\
Strabag \& Dywidag \& Heilit+Woerner & 296 & 51 & $13.3 \%$ & $9.1 \%$ & yes \\
Dragados \& Pol-Aqua \& Hochtief & 167 & 24 & $7.7 \%$ & $15.3 \%$ & yes \\
Mota-Engil & 157 & 25 & $5.6 \%$ & $7.2 \%$ & yes \\
Vinci \& Eurovia \& Warbud & 131 & 14 & $3.0 \%$ & $14.2 \%$ & yes \\
Acciona \& Mostostal Warszawa & 123 & 12 & $3.5 \%$ & $15.6 \%$ & yes \\
Porr \& Teerag & 87 & 12 & $4.4 \%$ & $14.6 \%$ & yes \\
Intercor & 81 & 9 & $2.1 \%$ & $22.2 \%$ & no \\
Bilfinger & 74 & 7 & $2.6 \%$ & $9.6 \%$ & yes \\
Astaldi & 70 & 9 & $4.5 \%$ & $14.3 \%$ & yes \\
Mirbud \& Kobylarnia & 67 & 7 & $1.0 \%$ & $28.6 \%$ & no \\
Aldesa & 60 & 3 & $0.6 \%$ & $31.6 \%$ & yes \\
Polimex-Mostostal & 57 & 7 & $3.6 \%$ & $10.7 \%$ & no \\
Mosty tódź & 57 & 5 & $1.1 \%$ & $21.4 \%$ & no \\
Skanska & 55 & 12 & $1.6 \%$ & $9.6 \%$ & yes \\
MSF & 51 & 2 & $0.9 \%$ & $11.7 \%$ & yes \\
Hermann Kirchner & 51 & 9 & $2.4 \%$ & $5.9 \%$ & yes \\
Salini \& Todini & 48 & 8 & $3.2 \%$ & $18.7 \%$ & yes \\
PBDM Mińsk Mazowiecki & 48 & 2 & $0.0 \%$ & $0.0 \%$ & no \\
Metrostav & 42 & 2 & $1.1 \%$ & $21.4 \%$ & yes \\
\hline Total share & $71.0 \%$ & $77.3 \%$ & $78.9 \%$ & - & -
\end{tabular}




\section{E Proofs of Propositions}

Proposition 1: For any $c_{i}$, the equilibrium bid of a firm $b^{*}\left(c_{i}\right)$ is a decreasing function of the number of entering bidders $n$ and of the number of potential entrants $k$.

Proof. Let us denote the entry function with $I\left(c_{i}, e_{i}\right):\left\{c_{i}, e_{i}\right\} \rightarrow\{0,1\}$, in which $I\left(c_{i}, e_{i}\right)=1$ indicates entry. First, we show that the set $\left\{c_{i}, e_{i}\right\}: I\left(c_{i}, e_{i}\right)=1$ is compact and satisfies the condition that $I\left(c_{i}, e_{i}\right) \geq I\left(c_{i}^{\prime}, e_{i}^{\prime}\right)$ if $c_{i}^{\prime} \geq c_{i}$ and $e_{i}^{\prime} \geq e_{i}$. That is, higher costs hinder entry. This result is derived directly from the entry condition $\max _{b_{i}} \mathbb{E}\left[\pi\left(b_{i}, b_{-i}, c_{i}\right)\right] \geq e_{i}$. For any strategy $b_{-i}$ of outside bidders, a higher entry cost $e_{i}$ means that there is a lower critical value of $c_{i}$ such that the condition is satisfied. The logic is similar for $c_{i}$.

The optimal bid does not depend on the entry cost, but only on $c_{i}$, as $e_{i}$ is the sunk cost at the point of bidding. Bidder $i$ faces the problem $\max _{b_{i}} \mathbb{E}\left[\pi\left(b_{i}, b_{-i}, c_{i}\right)\right]=\left(b_{i}-c_{i}\right) \cdot \operatorname{Pr}\left\{b_{i}=b_{1}\right\}$. We focus our attention on a symmetric equilibrium, in which the equilibrium bidding function is continuous. Conditional on that, the number of potential bidders equals $k$, the number of entries equals $n$, and the cumulative density function of bids is $F_{k}(b)$, the probability of winning is equal to the probability of $b_{i}$ being the lowest bid. Function $F_{k}(b)$ is conditional on the number of potential bidders $k$, as it determines the set of entering types, i.e. those $\left\{c_{i}, e_{i}\right\}$ for which $I\left(c_{i}, e_{i}\right)=1$. That is, the expected profit is

$$
\max _{b_{i}}\left(b_{i}-c_{i}\right) \cdot \operatorname{Pr}\left\{b_{i}=b_{1}\right\}=\left(b_{i}-c_{i}\right) \cdot\left(1-F_{k}\left(b_{i}\right)\right)^{n-1},
$$

where $\left(1-F_{k}\left(b_{i}\right)\right)^{n-1}$ expresses the probability that $b_{i}$ is smaller than other $n-1$ bids. ${ }^{38}$ For any $e_{i}, c_{i}$ has to satisfy that $\left(b_{i}-c_{i}\right) \cdot\left(1-F_{k}\left(b_{i}\right)\right)^{n-1} \geq e_{i}$. Let us denote the critical type with $\hat{c}_{i}\left(e_{i}, k\right)$ for which $\left(b_{i}-\hat{c}_{i}\left(e_{i}, k\right)\right) \cdot\left(1-F_{k}\left(b_{i}\right)\right)^{n-1}=e_{i}$. The first-order condition of (5) is

$$
-\left(b_{i}-c_{i}\right)(n-1) \cdot\left(1-F_{k}\left(b_{i}\right)\right)^{n-2} \cdot f_{k}\left(b_{i}\right)+\left(1-F_{k}\left(b_{i}\right)\right)^{n-1}=0,
$$

where $f_{k}\left(b_{i}\right)$ is the corresponding density function. The solution of this differential equation is

$$
b^{*}\left(c_{i}\right)=\underline{c}+\frac{\int_{c_{i}}^{c}\left(1-F_{k}(s)\right)^{n-1} d s}{\left(1-F_{k}\left(c_{i}\right)\right)^{n-1}},
$$

which is a decreasing function of $n$ (Milgrom, 2004).

\footnotetext{
${ }^{38} \mathrm{Here}$ we ignore ties as their probability is zero.
} 
Now, let us address the second part of the theorem. The auction stage profit is given by

$$
\left(c_{i}+\frac{\int_{c_{i}}^{c}\left(1-F_{k}(s)\right)^{n-1} d s}{\left(1-F_{k}\left(c_{i}\right)\right)^{n-1}}-\underline{c}\right) \cdot\left(1-F_{k}^{n-1}\left(c_{i}\right)\right),
$$

where the first term is the profit conditional on winning and the second term equals the probability of winning as a function of type and the number of entrants $n$. This expression is a decreasing function of $n$. In order to prove the theorem, we show that $\hat{c}\left(e_{i}, k\right)$ is decreasing in the potential number of bidders $k$. Suppose that $\hat{c}\left(e_{i}, k+1\right) \geq \hat{c}\left(e_{i}, k\right)$. Then, bidder $i$ with $c_{i}=\hat{c}\left(e_{i}, k\right)$ enters if the number of potential bidders is $k+1$. Given the bidding function is decreasing in $n$ and the ex ante probability of entry is larger, the profit of $i$ is lower than $e_{i}$, which is a contradiction. That is, $\hat{c}\left(e_{i}, k+1\right)<\hat{c}\left(e_{i}, k\right)$. It follows that the conditional cumulative density functions satisfy $F_{k+1}\left(c_{i}\right)=F_{k}\left(c_{i}\right) \frac{F\left(\hat{c}\left(e_{i}, k\right)\right)}{F\left(\hat{c}\left(e_{i}, k+1\right)\right)}>F_{k}\left(c_{i}\right)$. From (7), we obtain that the equilibrium bid is a decreasing function of $k$.

Proposition 2: For constant a $\alpha\left(e_{i}\right)=\alpha$, the marginal effect of $\alpha$ on entry is negative for firms with sufficiently low costs $c_{i}$, and positive for firms with sufficiently high costs $c_{i}$.

Proof. Entry occurs if a bidder's interim expected payoff is non-negative, hence

$$
\mathbb{E}\left[\Pi\left(b_{i}, b_{-i}, c_{i}, \alpha\left(e_{i}\right)\right)\right] \geq e_{i}
$$

where $\Pi\left(b_{i}, b_{-i}, c_{i}, \alpha\left(e_{i}\right)\right)$ is the auction payoff, conditional on entry, in an auction with a screening function $\alpha(\cdot)$. As in the baseline model, the set of types entering the auction is compact. The proof is identical to that of Proposition 1.

We denote the set of entering types by $\left\{c_{i}, e_{i}\right\}: I\left(c_{i}, e_{i}\right)=1$. Next, we characterize the bidding stage and focus on symmetric Bayesian equilibria with a strictly increasing continuous bidding function. Suppose that the number of potential entrants is $k, n$ bidders enter, and the conditional distribution function of bids is denoted by $F_{k, \alpha}(b)$.

The objective function of bidder $i$ is

$$
\begin{gathered}
\max _{b_{i}}\left(b_{i}-c_{i}\right) \cdot\left(\left(1-F_{k, \alpha}\left(b_{i}\right)\right)^{n-1} \cdot\left(1-\alpha\left(e_{i}\right)\right)+\int_{b_{i}}^{\bar{e}} \alpha(s) \cdot(n-1) \cdot F_{k, \alpha}\left(b_{i}\right) \cdot\left(1-F_{k, \alpha}\left(b_{i}\right)\right)^{n-2} d s\right)= \\
\max _{b_{i}}\left(b_{i}-c_{i}\right) \cdot\left(\left(1-F_{k, \alpha}\left(b_{i}\right)\right)^{n-1} \cdot\left(1-\alpha\left(e_{i}\right)\right)+(n-1) \cdot F_{k, \alpha}\left(b_{i}\right) \cdot\left(1-F_{k, \alpha}\left(b_{i}\right)\right)^{n-2} \cdot \int_{b_{i}}^{\bar{e}} \alpha(s) d s\right)
\end{gathered}
$$


Bidder $i$ may win in two cases, if $b_{i}$ is ranked first and is not rejected or it is ranked second, but the first-ranked bid is rejected. The baseline model is an extreme case in which $\alpha\left(e_{i}\right)=0$.

Now consider the case when the rejection function is constant, $\alpha\left(e_{i}\right)=\alpha \geq 0$. First, we calculate the expected price for the auctioneer given that $n$ firms enter. In a second-price auction it is a dominating strategy to bid one's own valuation, that is, the expected cost to the auctioneer is

$$
\begin{aligned}
\mathbb{E}\left((1-\alpha) \cdot b_{1}+\alpha \cdot b_{2}\right) & =\mathbb{E}\left((1-\alpha) \cdot c_{2}+\alpha \cdot c_{3}\right) \\
& =\mathbb{E}\left(c_{2}+\alpha \cdot\left(c_{3}-c_{2}\right)\right) .
\end{aligned}
$$

In this model we can use the Revenue Equivalence Theorem (Börgers, 2015). As types are independently drawn, utility is a linear function and the type space is convex, second and first-price auctions yield the same expected cost to the auctioneer. That is, (11) is the expected winning bid in the first-price auction. Formula (11) highlights an important property of using screening. With a given entry, it substitutes the winning bid with a more expensive offer with probability $\alpha$. Using payoff equivalence (Börgers, 2015), the expected payoff of the winner conditional on facing $n-1$ other entrants equals

$$
\begin{array}{r}
\left(\mathbb{E}\left(c_{2} \mid c_{i}=c_{1}\right)-c_{i}\right) \cdot(1-\alpha) \cdot\left(1-F_{k}\left(c_{i}\right)\right)^{n-1}+ \\
\left(\mathbb{E}\left(c_{3} \mid c_{i}=c_{2}\right)-c_{i}\right) \cdot \alpha \cdot(n-1) \cdot F_{k}\left(c_{i}\right) \cdot\left(1-F_{k}\left(c_{i}\right)\right)^{n-2}
\end{array}
$$

The first term corresponds to the case if bidder $i$ wins and the second term is the expected payoff from winning as the second lowest bidder.

For example, the chance that exactly $n$ bidders decide to submit a bid equals $\left(\begin{array}{l}n \\ k\end{array}\right)\left(\int_{\underline{e}}^{\bar{e}} \hat{c}_{i}\left(e_{i}\right)\right)^{n}$. $\left(1-\left(\int_{\underline{e}}^{\bar{e}} \hat{c}_{i}\left(e_{i}\right)\right)\right)^{k-n}$. From this, the expected payoff with cost $c_{i}$ equals

$$
\begin{array}{r}
\sum_{n=1}^{k}\left(( \begin{array} { l } 
{ n } \\
{ k }
\end{array} ) \cdot \left(\left(\mathbb{E}\left(c_{2} \mid c_{i}=c_{1}\right)-c_{i}\right)(1-\alpha)\left(1-F_{k}\left(c_{i}\right)\right)^{n-1}+\right.\right. \\
\left.\left.\left(\mathbb{E}\left(c_{3} \mid c_{i}=c_{2}\right)-c_{i}\right) \alpha(n-1) F_{k}\left(c_{i}\right)\left(1-F_{k}\left(c_{i}\right)\right)^{n-2}\right)\right) .
\end{array}
$$

The most competitive type with cost $c_{i}=\underline{c}$ clearly suffers from a higher $\alpha$ as $\lim _{c_{i} \rightarrow \underline{c}}=F_{k}\left(c_{i}\right)=$ 0 . Similarly, bidders with a very high type enjoy a higher $\alpha$. For constant $\alpha\left(e_{i}\right)=\alpha$, there is a right-side environment of $\underline{c}$ on which the marginal entry effect of $\alpha$ is negative on entry, and there is a right-side environment of $\bar{c}$ on which it is positive. 
○— @

www.ibs.org.pl 